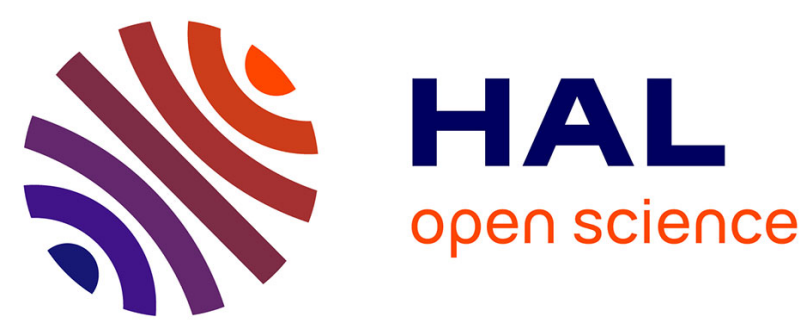

\title{
Nickel N-Heterocyclic Carbene-Catalyzed C-Heteroatom Bond Formation, Reduction, and Oxidation: Reactions and Mechanistic Aspects
}

Vincent Ritleng, Mickaël Henrion, Michael J Chetcuti

\section{- To cite this version:}

Vincent Ritleng, Mickaël Henrion, Michael J Chetcuti. Nickel N-Heterocyclic Carbene-Catalyzed CHeteroatom Bond Formation, Reduction, and Oxidation: Reactions and Mechanistic Aspects. ACS Catalysis, 2016, 6 (2), pp.890-906. 10.1021/acscatal.5b02021 . hal-03478074

\section{HAL Id: hal-03478074 \\ https://hal.science/hal-03478074}

Submitted on 13 Dec 2021

HAL is a multi-disciplinary open access archive for the deposit and dissemination of scientific research documents, whether they are published or not. The documents may come from teaching and research institutions in France or abroad, or from public or private research centers.
L'archive ouverte pluridisciplinaire HAL, est destinée au dépôt et à la diffusion de documents scientifiques de niveau recherche, publiés ou non, émanant des établissements d'enseignement et de recherche français ou étrangers, des laboratoires publics ou privés. 


\section{Nickel N-Heterocyclic Carbene-Catalyzed C-}

\section{Heteroatom Bond Formation, Reduction and}

\section{Oxidation: Reactions and Mechanistic Aspects}

Vincent Ritleng, ${ }^{* * * *}$ Mickaël Henrion, and Michael J. Chetcuti **

$\dagger$ Laboratoire de Chimie Organométallique Appliquée, UMR CNRS 7509, Ecole européenne de Chimie, Polymères et Matériaux, Université de Strasbourg, 25 rue Becquerel, 67087 Strasbourg, France. $\ddagger$ Institut Universitaire de France, 103 boulevard Saint Michel, 75005 Paris, France.

ABSTRACT: The chemistry of nickel(N-heterocyclic carbene) species has blossomed at the beginning of this century with a particularly rapid acceleration in the last 5 years, as indicated by the fact that more than $65 \%$ of the discussed research articles in this comprehensive review date from the period 2010-2015. The rapid evolution of this chemistry has led to an increasing number of applications in the field of catalytic $\mathrm{C}$-heteroatom bond formation, reduction and oxidation where the heteroatom is either nitrogen, sulfur, oxygen or boron. Thus, in addition to the development of aryl aminations, aryl thiolations, alkyne hydrothiolations, and transfer hydrogenations, which are the most ancient reactions of this type known for these systems, the last five years have seen the appearance of a number of novel interesting $\mathrm{Ni}(\mathrm{NHC})$-catalyzed transformations such as the dehydrogenative cross-coupling of aldehydes and amines or alcohols, the hydroamination of alkenes, the hydroimination of alkynes, a one-step indoline synthesis, 
(cross)-Tishchenko reactions, the borylation of unsaturated $\mathrm{C}-\mathrm{C}$ bonds and arenes, the borylative cleavage of $\mathrm{C}-\mathrm{N}$ bonds, the hydrosilylation of $\mathrm{C}-\mathrm{O}$ and $\mathrm{C}-\mathrm{N}$ multiple bonds, the reductive cleavage of aromatic $\mathrm{C}-\mathrm{O}$ bonds, and the anaerobic oxidation of alcohols. This rapid expansion calls for a review of the state of the art at this time with a special emphasis on mechanistic data to allow new insights into catalyst improvement.

KEYWORDS: nickel, N-heterocyclic carbene, catalysis, C-Heteroatom bond, formation, reduction, oxidation, reaction mechanism

\section{INTRODUCTION}

After an intense period of research into the chemistry of nickel complexes' that started after the discovery of the "nickel effect" by Ziegler and Holzkamp in the mid 1950s, ${ }^{2}$ and culminated with the establishment of a number of important industrial processes, ${ }^{3}$ such as the DuPont adiponitrile process $^{34}$ and the Shell Higher Olefin Process, ${ }^{35}$ nickel's chemistry has long been eclipsed by those of the noble metals, in particular that of its $d^{\text {in }}$ counterpart palladium. The importance of the latter was notably highlighted by the attribution of the 2010 Nobel Prize in Chemistry to Richard F. Heck, Ei-ichi Negishi and Akira Suzuki "for palladium-catalyzed cross couplings in organic synthesis". ${ }^{67}$

Nickel's time in catalysis, however, has returned with a vengeance. Driven by declining natural reserves of precious metals and their consequent tremendous price increases, the development of catalytic reactions based on inexpensive earth-abundant materials has become a key strategic issue as highlighted by a recent report from the European Commission. ${ }^{8}$ Among other first-row metals, such as iron, cobalt and copper, nickel in particular offers interesting perspectives. It is cheap; on a molar basis, nickel costs $0.05 \%$ of the price of palladium and 
$0.01 \%$ of the price of platinum. But more importantly, nickel presents a number of characteristics that makes of it much more than just "ersatz palladium". ${ }^{\circ}$ For instance, it is more nucleophilic than palladium, and thus favors the oxidative addition of less common electrophiles than aryl halides, such as phenol derivatives ${ }^{10.11}$ or aryl fluorides..$^{12}$ Moreover, nickel offers a more facile access to multiple oxidation states: nickel(0) and nickel(II) species allow relatively easy access to $\mathrm{Ni}(\mathrm{I}), \mathrm{Ni}(\mathrm{III})$ and even $\mathrm{Ni}(\mathrm{IV})^{13}$ oxidation states and this renders radical reaction pathways more accessible. Thus in addition to $\mathrm{Ni}(0) / \mathrm{Ni}(\mathrm{II})$ pathways, fascinating transformations involving $\mathrm{Ni}(\mathrm{I}) / \mathrm{Ni}(\mathrm{III}){ }_{{ }^{14}} \mathrm{Ni}(0) / \mathrm{Ni}(\mathrm{II}) / \mathrm{Ni}(\mathrm{III}) / \mathrm{Ni}(\mathrm{I})^{1516}$ or all-Ni(I) ${ }^{17}$ catalytic cycles are also possible.

Since the first isolation of a stable imidazol-2-ylidene by Arduengo in $1991,^{18} \mathrm{~N}$-heterocyclic carbenes (NHCs) have revolutionized organometallic chemistry in many aspects. Their tremendous success is due to the combination of several factors. Firstly, NHCs are based on inexpensive and non-air-sensitive imidazolium salt precursors and are generally easy to access..$^{19}$ Secondly, owing to their strong $\sigma$-donor properties, they form stronger bonds with metal centers than most classical ligands, including trialkylphosphines. ${ }^{20}$ Moreover, they offer significant steric protection to a metal in a metal-NHC complex while retaining the tunability of electronic and steric properties, principally via functionalization of the backbone and permutations of the $\mathrm{N}$ bound hydrocarbyl substituents. Thus, as observed for other metals, ${ }^{21}$ the use of NHC ligands in place of phosphine or amine ligands in nickel chemistry has led to an important enrichment of the observed catalytic activity, and thus to the significant diversification of nickel-based systems.

Catalytic applications of $\mathrm{Ni}(\mathrm{NHC})$ complexes, that, in addition to those reviewed in here, include reactions as varied as $\mathrm{C}-\mathrm{C}$ cross-couplings, $\mathrm{C}-\mathrm{H}$ bond functionalizations, threecomponent couplings of unsaturated hydrocarbons, aldehydes, and silyl derivatives, $[2+2+2]$ cycloadditions, olefin oligo- and polymerization, the dehalogenation of aryl halides, and the 
hydrosilylation of internal alkynes have already been reviewed in several articles and book chapters, ${ }^{22}$ but the field is evolving extremely rapidly and these reviews are either already outdated,$^{2+2 a c}$ or very general, ${ }^{2 a d e}$ and in general, did not focus on mechanistic aspects. Herein, we have attempted to encompass all examples involving these species, as either in situ generated species or as well-defined catalysts, in C-heteroatom bond formation, and in reduction and oxidation reactions where the heteroatom is either nitrogen, sulfur, oxygen or boron.$^{23}$ In addition, we have tried to give as much mechanistic details as possible. Coverage should be comprehensive till the end of July 2015.

\section{CARBON-NITROGEN BOND FORMATION}

\subsection{Cross-Coupling Methodologies}

2.1.1. The Amination of Aryl Halides. Palladium- or nickel-mediated coupling of aryl halides with amines has attracted significant interest because of the use of this methodology in organic synthesis and in material science. ${ }^{24}$ The long-going studies of Hartwig and Buchwald, in particular, have shown that the supporting ligands on the metal center play a crucial role in dictating the efficiency of the catalytic system. ${ }^{24}$ In this respect, the influence of NHC ligands has of course been evaluated, and the first $\mathrm{Ni}(\mathrm{NHC})$-catalyzed amination of aryl halides was reported by Fort et al. as early as $2001{ }^{25}$ In this seminal account, the authors used a $\mathrm{Ni}(\mathrm{acac}) / \mathrm{SIPr} \cdot \mathrm{HCl}$ (1:4) combination in the presence $t-\mathrm{BuOH}$ and excess $\mathrm{NaH}$ to couple aryl chlorides with a small variety of secondary cyclic or acyclic amines with moderate to excellent efficacy. The principal drawback of this initial method was the use of an excess of $\mathrm{NaH}$, which decreased the compatibility of the reaction with functional groups and thus narrowed the scope. Further work however showed that employing the minimum required amount of $\mathrm{NaH}$ to reduce the starting 
$\mathrm{Ni}(\mathrm{II})$ catalyst precursor to $\mathrm{Ni}(0)$ and to convert $t$ - $\mathrm{BuOH}$ to $\mathrm{NaO} t$ - $\mathrm{Bu}$ was enough to maintain the activity of the $\mathrm{Ni}(0)$ catalyst with an excellent efficiency ${ }^{26}$ In these conditions, a large array of aryl chlorides was coupled to a good variety of secondary amines and anilines, and even to a couple of primary amines (Scheme 1). Of note, slightly harsher conditions were required for the coupling of anilines and primary amines compared to that of secondary amines; reflux in 1,4dioxane and higher loadings of $\mathrm{Ni}(\mathrm{acac})_{2}$ and/or $\mathrm{SIPr} \cdot \mathrm{HCl} v s$. reflux in THF with $5 \mathrm{~mol} \%$ of a 1:1 $\mathrm{Ni}(\mathrm{acac})_{2} / \mathrm{SIPr} \cdot \mathrm{HCl}$ combination. Remarkably, similar conditions later also allowed the intramolecular coupling of aryl chlorides with amines to yield 5- to 7-membered $\mathrm{N}$ heterocycles ${ }^{27}$ as well as the selective mono- or diarylation of aromatic diamines.$^{28}$

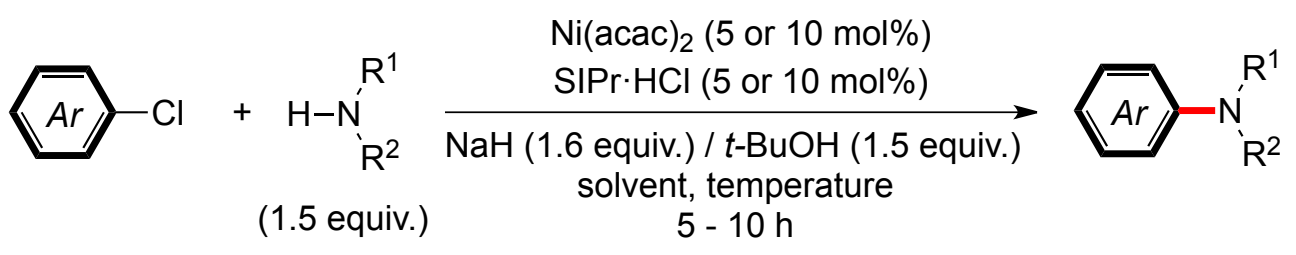

$\begin{array}{lc}\text { Secondary amines: } \mathrm{THF}, 65^{\circ} \mathrm{C}, \mathrm{Ni}(\mathrm{acac})_{2}(5 \mathrm{~mol} \%), \mathrm{SIPr} \cdot \mathrm{HCl}(5 \mathrm{~mol} \%) & 25 \text { examples } \\ 53-99 \% & 22 \text { examples } \\ & 47-99 \% \\ \text { Anilines: dioxane, } 100{ }^{\circ} \mathrm{C}, \mathrm{Ni}(\mathrm{acac})_{2}(5 \mathrm{~mol} \%), \mathrm{SIPr} \cdot \mathrm{HCl}(10 \mathrm{~mol} \%) & \begin{array}{c}3 \text { examples } \\ 37-85 \%\end{array}\end{array}$

Scheme 1. First Ni(NHC)-Catalyzed Amination of Aryl Chlorides ${ }^{26}$

There is little mechanistic information about the arylaminations conducted with the $\mathrm{Ni}(0) / \mathrm{SIPr} \cdot \mathrm{HCl} / \mathrm{NaO} t$-Bu catalytic combination. Nevertheless the authors of this series of papers provided some clues. First of all, the role of the in situ generated $\mathrm{NaO} t$-Bu would be two-fold during the preparation of the active catalytic species: it would (i) activate the $\mathrm{NaH}$ used to reduce the $\mathrm{Ni}(\mathrm{II})$ salt to $\mathrm{Ni}(0)$, and (ii) deprotonate $\mathrm{SIPr} \cdot \mathrm{HCl}$ to produce the carbene ligand, which would coordinate to the nickel center. ${ }^{252628}$ Secondly, transmission electron microscopy coupled energy- 
dispersive X-ray spectra of the thus obtained catalyst revealed a homogeneous distribution of uniformly sized amorphous and subnanometrical $\mathrm{Ni}(0)$ particles..$^{2526}$ Thirdly, in the particular case of a 1:2 $\mathrm{Ni}(\mathrm{acac})_{2} / \mathrm{IPr} \cdot \mathrm{HCl}$ catalytic combination, ${ }^{\mathrm{a}} \mathrm{C} \mathrm{NMR}$ spectroscopy done after treatment with $\mathrm{NaO}$-Bu-activated $\mathrm{NaH}$ revealed that the active species is very likely to be a $\mathrm{Ni}^{\circ} \mathrm{IPr}_{2}$ complex. ${ }^{28}$ Finally, the authors proposed a catalytic cycle that is similar to that postulated for the palladium-catalyzed aryl/amination using $\mathrm{Pd} /$ carbene systems with oxidative addition of the aryl chloride as the first step, coordination and deprotonation of the amine as the second and third step, and reductive elimination of the coupling product, which would be favored by the important steric bulk of the SIPr ligand, as the final step (Scheme 2). ${ }^{26}$

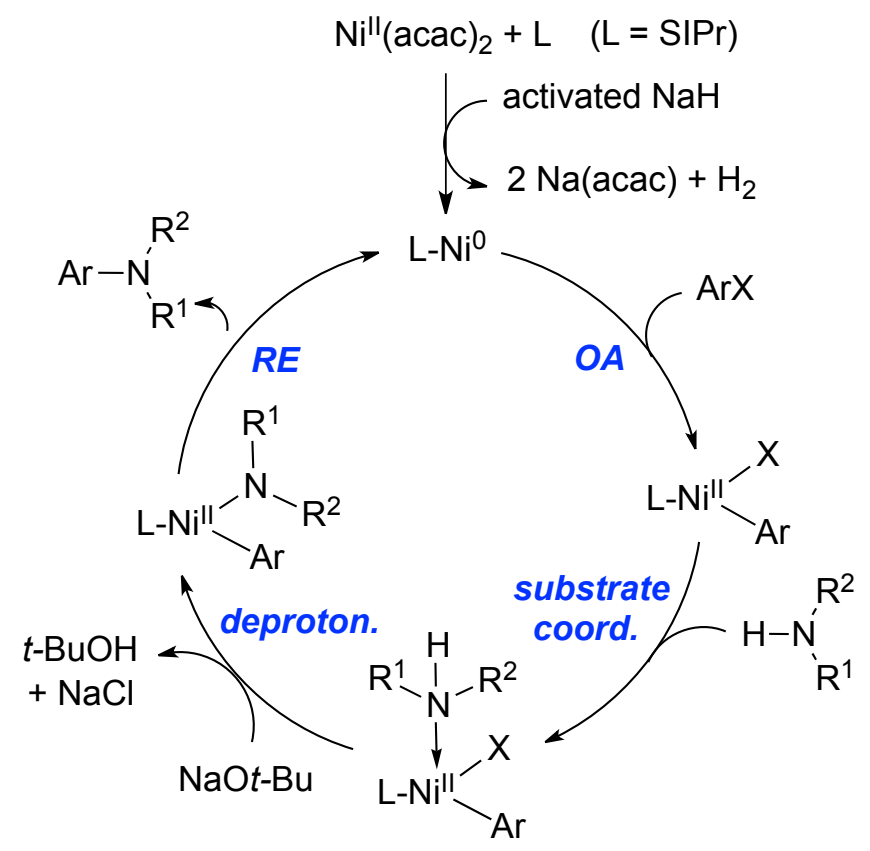

Scheme 2. Proposed Mechanism for the Amination of Aryl Chlorides ${ }^{26}$

Interestingly by using the inexpensive and environmentally friendly polymethylhydroxysilane (PMHS) instead of $\mathrm{NaH}$ as a reducing agent with the same catalyst precursor combination, Knochel et al. were able to dramatically decrease the catalyst loading to $0.1 \mathrm{~mol} \%$ for the 
coupling of 1-chloro-4-trifluoromethyl-benzene with pyrrolidine (Scheme 3). ${ }^{29}$ Similar or even better results were obtained with phenanthroline ligands and the scope was unfortunately not studied with $\mathrm{Ni}(\mathrm{acac})_{2} / \mathrm{IPr} \cdot \mathrm{HCl}$.

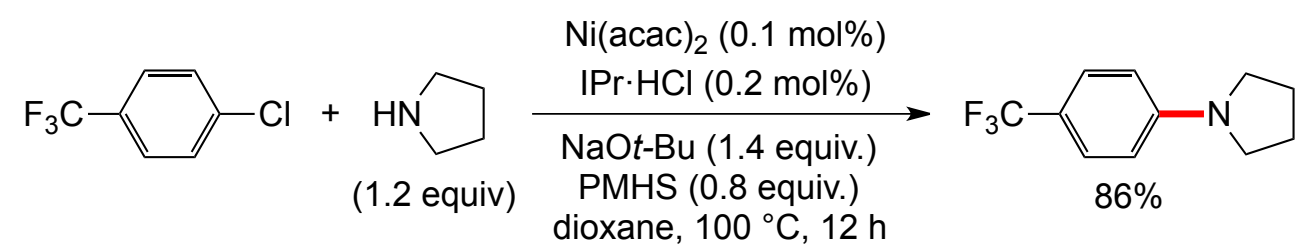

Scheme 3. $\mathrm{Ni}(\mathrm{acac})_{2} / \mathrm{IPr} \cdot \mathrm{HCl}-\mathrm{Catalyzed}$ Arylamination with PMHS as a Reducing Agent ${ }^{29}$

Similarly, in the presence of $\mathrm{NaO} t-\mathrm{Bu}$ as base and phenylboronic acid pinacol ester ( $\mathrm{Ph}-\mathrm{Bpin})$ as a mild reducing agent, a 1:2 combination of $\mathrm{NiCl}_{2} \cdot(\mathrm{DME})$ and $\mathrm{SIPr} \cdot \mathrm{HCl}$ was shown to exhibit an interesting activity, albeit with rather high loadings, towards the amination of aryl sulfamates and carbamates, which are attractive aryl halide surrogates owing to their ease of preparation and handling, their low toxicity, and their low cost (Scheme 4).$^{30}$ Moreover, the scope of the method was shown to be broad with respect to both coupling partners, including ring-fused, orthosubstituted-phenyl and heterocyclic electrophiles, and cyclic and acyclic secondary amines and anilines. Very interestingly, this methodology was recently also shown to proceed in the green solvent, 2-methyl-THF, and to be applicable, under these conditions, on gram scales with catalyst loadings as low as $1 \mathrm{~mol} \%{ }^{31}$ Finally, using the acenaphtoimidazolium chloride 1 depicted in Scheme 5 instead of SIPr $\cdot \mathrm{HCl}$ allowed the coupling of bulky ring-fused aryl and heteroaryl tosylates with cyclic secondary amines, primary amines and anilines in the presence of a catalyst loading of only $2 \mathrm{~mol} \%$ in dioxane at $100{ }^{\circ} \mathrm{C}$, under otherwise comparable conditions..$^{32}$ 


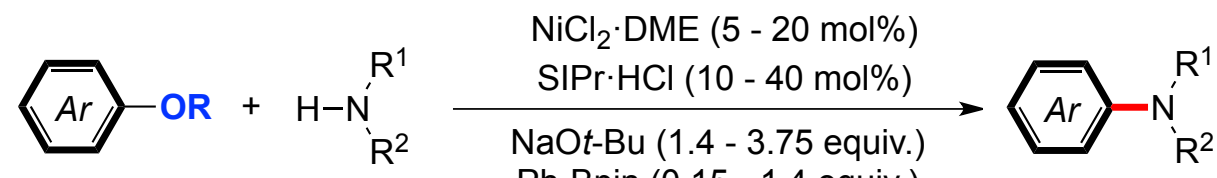

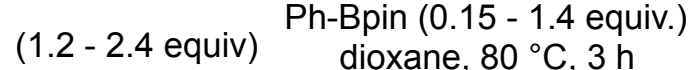

$$
\begin{aligned}
& \begin{array}{ll}
\mathrm{OR}=\mathrm{OS}(\mathrm{O})_{2} \mathrm{NMe}_{2} & 22 \text { examples } \\
& 53-98 \%
\end{array} \\
& \mathrm{OR}=\mathrm{OC}(\mathrm{O}) \mathrm{NEt}_{2} \quad 22 \text { examples } \\
& 40-91 \%
\end{aligned}
$$

Scheme 4. $\mathrm{NiCl}_{2} \cdot(\mathrm{DME}) / \mathrm{SIPr} \cdot \mathrm{HCl}-\mathrm{Catalyzed}$ Arylamination with Ph-Bpin as a Reducing Agent ${ }^{30}$

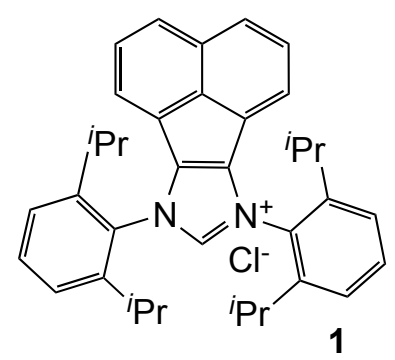

Scheme 5. Structure of the Acenaphtoimidazolium Chloride $\mathbf{1}$ used in Combination with $\mathrm{NiCl}_{2} \cdot(\mathrm{DME})$ for the Amination of Aryl and Heteroaryl Tosylates ${ }^{32}$

Inspired by the seminal work of Kochi et al.,33 Yang and co-workers reasoned that in the hypothesis of a $\mathrm{Ni}(0)-\mathrm{Ni}(\mathrm{II})$ catalytic cycle, air-stable aryl-nickel(II)-halide complexes may formally be regarded as oxidative adducts in the catalytic cycle, and may thus have the ability to in situ generate an active $\mathrm{Ni}(0)$ species without the aid of a reducing agent, i.e.: by attack of a nucleophile and subsequent reductive elimination prior to the catalytic cycle (Scheme 6$).^{3435}$

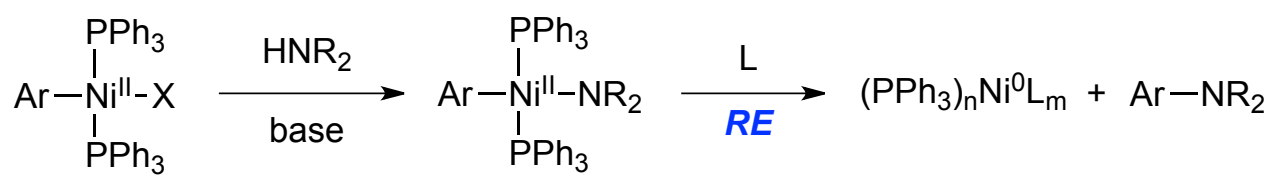

Scheme 6. Possible Pathway for Activating Aryl-Nickel(II)-Halide Complexes ${ }^{34}$ 
Indeed by employing trans-[Ni(PPh $\left.)_{2}(\mathrm{Ph}) \mathrm{Br}\right](2)$ or trans-[Ni( $\left.\mathrm{PPh}_{3}\right)_{2}\{1$-(p-acetylnaphtyl $\left.\left.)\right\} \mathrm{Br}\right]$ (3) in combination with $\mathrm{IPr} \cdot \mathrm{HCl}$ in a 1:1 or 1:2 ratio, and $\mathrm{NaO} t-\mathrm{Bu}$ as the sole additive, they were able to couple some cyclic secondary amines and anilines with several aryl chlorides in moderate to excellent yields in THF and/or dioxane under temperatures ranging from 65 to $120{ }^{\circ} \mathrm{C}$ (Scheme 7). ${ }^{34}$ It is noteworthy that the reaction is strongly base and solvent dependent. Thus, more recent work showed that by using 4 equiv. of $\mathrm{KO} t$ - $\mathrm{Bu}$ and changing the solvent to toluene, a 1:1 combination of trans-[Ni( $\left.\mathrm{PPh}_{3}\right)_{2}(1-$ naphtyl) Br] $\mathbf{4}$ and $\mathrm{IPr} \cdot \mathrm{HCl}$ can catalyze the coupling of a series of aryl and heteroaryl chlorides with morpholine, piperidine and pyrrolidine at room temperature (Scheme 7). ${ }^{36}$ Acyclic secondary amines and anilines however proved to be unreactive under these conditions. The same catalytic system with $\mathrm{NaO} t$ - $\mathrm{Bu}$ as base was also efficient for the coupling of some aryl tosylates with the same cyclic secondary amines, and a few anilines when reacted in dioxane at reflux (Scheme 7). ${ }^{37}$ Impressively, the reactions were completed in only 15 to $30 \mathrm{~min}$, but the scope was rather limited and, for instance, electron-rich tosylates were unsuitable for the reaction. Finally, perhaps the most interesting results of these series of papers authored by Yang et al. were observed when using aryl phosphates, which are even more benign than other $\mathrm{C}-\mathrm{O}$ electrophiles, as coupling partners ${ }^{38}$ Indeed, in the presence of $\mathrm{NaH}$ as a base, $\mathbf{2} / \mathrm{IPr} \cdot \mathrm{HCl}$ (1:1) efficiently catalyzed the coupling of a large variety of aryl phosphates with cyclic secondary amines, anilines and even primary aliphatic amines in dioxane at $110{ }^{\circ} \mathrm{C}$ in $30 \mathrm{~min}$ to $1 \mathrm{~h}$ (Scheme 7). 


\begin{tabular}{|c|c|c|}
\hline$-\mathrm{X}+\underset{(1-3 \text { equiv. })}{\mathrm{H}-\mathrm{N}_{\mathrm{R}^{2}}^{\mathrm{R}^{1}}} \frac{\begin{array}{c}2-4(3-5 \mathrm{~mol} \%) \\
\mathrm{IPr} \cdot \mathrm{HCl}(3-10 \mathrm{~mol} \%)\end{array}}{\text { base, solvent, temperature }}$ & $\mathrm{R}^{1}$ & $\begin{array}{r}\mathrm{PPh}_{3} \\
\mathrm{Ar}-\mathrm{Ni}-\mathrm{X} \\
\mid \\
\mathrm{PPh}_{3}\end{array}$ \\
\hline \multicolumn{2}{|l|}{$\mathrm{X}=\mathrm{Cl}$ and cyclic secondary amines: } & $3: \mathrm{Ar}=1-(p$-acetylnaphtyl) \\
\hline \multirow{2}{*}{$\begin{array}{l}2(3 \mathrm{~mol} \%), \mathrm{IPr} \cdot \mathrm{HCl}(3 \mathrm{~mol} \%), \mathrm{NaOt}-\mathrm{Bu}(1.3 \text { equiv. }) \\
\mathrm{THF}\left(65^{\circ} \mathrm{C}\right) \text { or dioxane }\left(80^{\circ} \mathrm{C}\right), 1-3 \mathrm{~h}\end{array}$} & 9 examples & $\begin{aligned} X & =C l \\
\text { A. } & =1\end{aligned}$ \\
\hline & 72 - 99\% [ref. 34] & \\
\hline $\begin{array}{l}4(5 \mathrm{~mol} \%), \mathrm{IPr} \cdot \mathrm{HCl}(5 \mathrm{~mol} \%), \mathrm{KOt}-\mathrm{Bu}(4.0 \text { equiv.), } \\
\text { toluene (RT), } 24 \mathrm{~h}\end{array}$ & $\begin{array}{l}19 \text { examples } \\
50-99 \% \text { [ref. 36] }\end{array}$ & \\
\hline \multicolumn{3}{|l|}{$\mathrm{X}=\mathrm{Cl}$ and anilines: } \\
\hline \multirow{2}{*}{$\begin{array}{l}3(5 \mathrm{~mol} \%), \mathrm{IPr} \cdot \mathrm{HCl}(10 \mathrm{~mol} \%), \mathrm{NaOt}-\mathrm{Bu}(1.3 \text { equiv. }) \\
\text { dioxane }\left(100-120^{\circ} \mathrm{C}\right), 3-6 \mathrm{~h}\end{array}$} & 10 examples & \\
\hline & $66-99 \%$ [ref. 34] & \\
\hline \multicolumn{3}{|l|}{$\mathrm{X}=\mathrm{OTs}$ and cyclic secondary amines: } \\
\hline \multirow{2}{*}{$\begin{array}{l}4(5 \mathrm{~mol} \%), \mathrm{IPr} \cdot \mathrm{HCl}(5 \mathrm{~mol} \%), \mathrm{NaOt}-\mathrm{Bu}(1.6 \text { equiv. }) \\
\text { dioxane }\left(110^{\circ} \mathrm{C}\right), 15 \mathrm{~min}\end{array}$} & 14 examples & \\
\hline & $24-96 \%$ [ref. 37] & \\
\hline \multicolumn{3}{|l|}{$X=O T s$ and anilines: } \\
\hline 4 (5 mol\%), IPr. $\mathrm{HCl}(10 \mathrm{~mol} \%), \mathrm{NaOt}-\mathrm{Bu}(1.6$ equiv.) & 19 examples & \\
\hline dioxane $\left(110^{\circ} \mathrm{C}\right), 30 \mathrm{~min}$ & $37-95 \%$ [ref. 37] & \\
\hline \multicolumn{3}{|c|}{$\mathrm{X}=\mathrm{OP}(\mathrm{O})(\mathrm{OAr})_{2}$ and cyclic secondary amines, aliphatic primary amines and anilines } \\
\hline \multirow{2}{*}{4 (5 mol\%), IPr. $\mathrm{HCl}(10 \mathrm{~mol} \%), \mathrm{NaH}$ (2.0 equiv.) } & 28 examples & \\
\hline & $21-95 \%$ [ref. 38] & \\
\hline
\end{tabular}

Scheme 7. Aryl-Nickel(II)-Halide/IPr·HCl-Catalyzed Amination of Aryl Chlorides, Tosylates and Phosphates ${ }^{343638}$

Regarding the mechanism, indirect evidence of the generation of a $\mathrm{Ni}(0)$ active species as postulated in Scheme $6^{34}$ was furnished by the detection, in all experiments conducted with 4/IPr $\cdot \mathrm{HCl}$, of a small amount of the 1-naphtyl amination byproduct, ${ }^{3738}$ and by the result of stoichiometric reactions between $2 / \mathrm{IPr} \cdot \mathrm{HCl}$ or $4 / \mathrm{IPr} \cdot \mathrm{HCl}$ with morpholine in the presence of $\mathrm{NaO} t \mathrm{Bu}$, which, in both cases, gave the arylamination coupling product..$^{34}$ These results, along with previous studies on nickel-catalyzed cross-coupling reactions, ${ }^{26^{3.9}}$ prompted the authors to propose the catalytic cycle depicted in Scheme 8, which classically involves sequential oxidative addition, transmetalation and reductive elimination after generation of the active $\mathrm{Ni}(0)$ species by transmetalation of the nucleophilic reactant and subsequent reductive elimination of the 1-aryl amination byproduct. Of note, the higher activity observed with $\mathbf{2 - 4} / \mathrm{IPr} \cdot \mathrm{HCl}$ compared to Fort's 
system - illustrated by the lower catalyst loadings and much shorter reaction times - was tentatively attributed to the fact that the active $\mathrm{Ni}(0)$ species might be colligated with $\operatorname{IPr}$ and $\mathrm{PPh}_{3}$. Thus, the presence of the highly $\sigma$-donating IPr ligand would facilitate the oxidative addition step, while that of $\mathrm{PPh}_{3}$ associated to the steric bulk of IPr would accelerate the reductive elimination step. ${ }^{3437}$ In addition, $\mathrm{PPh}_{3}$ could be labile, thus dissociating from nickel to provide a vacant coordination site for the oxidative addition step, and re-coordinating to accelerate the reductive elimination step by an increase of the steric effect..$^{37}$

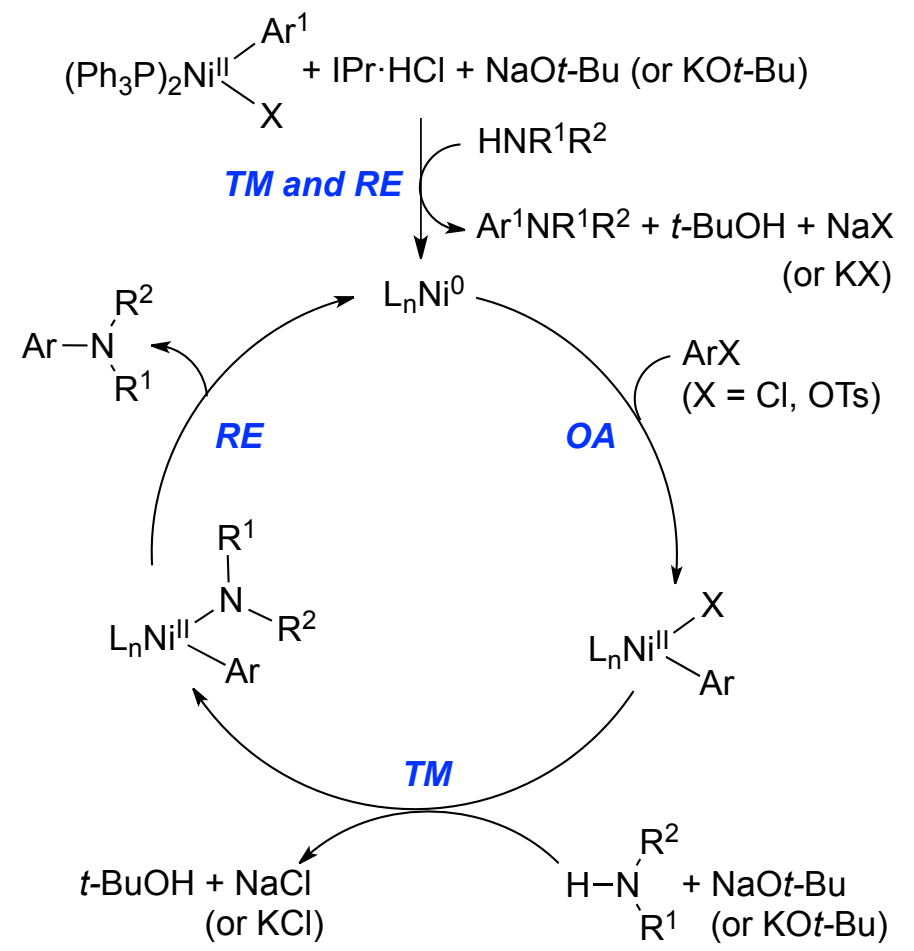

Scheme 8. Proposed Mechanism for the Amination of Aryl Chlorides and Tosylates Catalyzed by Aryl-Nickel(II)-Halide/IPr·HCl Systems ${ }^{3,37}$

Very recently, use of the simpler $\left[\mathrm{NiCl}_{2}\left(\mathrm{PPh}_{3}\right)_{2}\right] / \mathrm{IPr} \cdot \mathrm{HCl}(1: 2)$ system under similar conditions (i.e.: in the absence of a reducing agent and in the sole presence of $\mathrm{NaO} t$ - $\mathrm{Bu}$ as base) allowed the coupling of benzophenone hydrazone with a series of bromoarenes in moderate to good yields 
(Scheme 9). ${ }^{40}$ Other hydrazine surrogates did not undergo the cross-coupling reaction, and the reaction is intolerant to functional groups such as cyano and ester groups, which were found to react with the free amino group of benzophenone hydrazone. No explanation was given to rationalize the rather surprising activity of the nickel(II) catalyst precursor under these conditions, but one may consider a synergetic action of the IPr and $\mathrm{PPh}_{3}$ ligands, similar to that proposed for the $\left[\mathrm{Ni}(\mathrm{Ar}) \mathrm{X}\left(\mathrm{PPh}_{3}\right)_{2}\right] / \mathrm{IPr} . \mathrm{HCl}$ system (see Schemes 7 and 8).

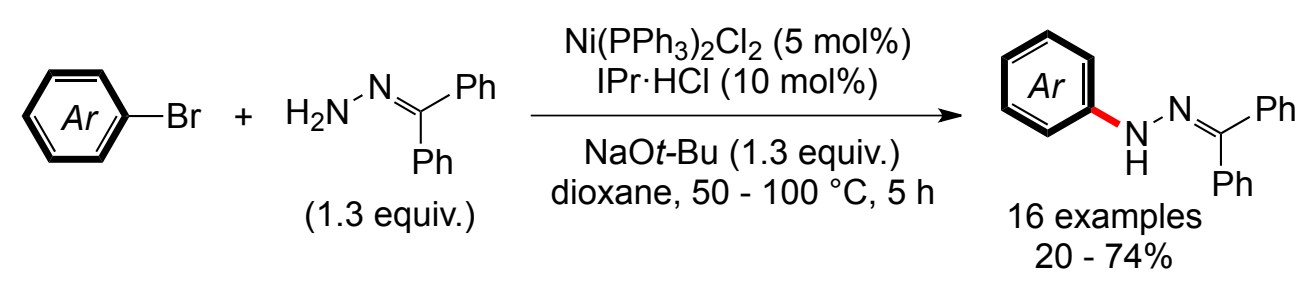

Scheme 9. $\left[\mathrm{NiCl}_{2}\left(\mathrm{PPh}_{3}\right)_{2}\right] / \mathrm{IPr} \cdot \mathrm{HCl}-$ Catalyzed Amination of Bromoarenes with Benzophenone Hydrazone $e^{\text {to }}$

Given the results observed with nickel(II) catalyst precursors (vide supra), the direct use of a nickel(0) source with an imidazolium salt and a base, logically, also proved to be very efficient. Thus, 1:2 combinations of $\mathrm{Ni}(\mathrm{COD})_{2} / \mathrm{IPr} \cdot \mathrm{HCl}$ or $\mathrm{SIPr} \cdot \mathrm{HCl}$ in the presence of $\mathrm{NaO} t-\mathrm{Bu}$ as base were shown, by several groups, to promote the amination of phenolic-derived electrophiles such

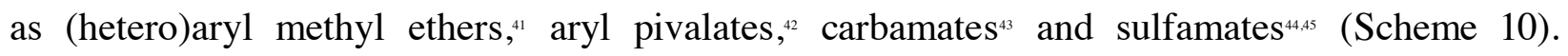
Nevertheless, reactions with aryl or heteroaryl methyl ethers proceeded efficiently only with 2methoxynaphtalenes ${ }^{\text {ta }}$ or methoxy-substituted $N$-fused heteroarenes or pyridines ${ }^{\text {st }}$ and cyclic secondary amines, moreover in the presence of high catalyst (20 mol\%), base (6 equiv.) and amine (5 equiv.) loadings, which limited their synthetic application. By contrast, aryl pivalates proved more reactive and allowed a broader scope - both cyclic and acyclic secondary amines could be coupled with a wide variety of electron-rich and electron-poor aryl pivalates - under 
significantly milder reaction conditions (Scheme 10)..$^{42}$ Interestingly, aryl carbamates ${ }^{43}$ and sulfamates ${ }^{4+45}$ allowed relatively large scope as they could be coupled with both cyclic and acyclic secondary amines as well as with anilines in moderate to excellent yields. However it must be pointed out that in several cases, notably with electron-rich and ortho-substituted aryl carbamates and sulfamates on one hand, and with anilines on the other, the catalyst loading had to be increased up to $20 \mathrm{~mol} \%$. Thus, although these conditions have been used in sequential siteselective cross-couplings ${ }^{43}$ and in a concise synthesis of the antibacterial drug, linezolid," they considerably reduce the methods' practicality. It must also be pointed out that in toluene at 105 ${ }^{\circ} \mathrm{C}, 1,1$ '-bis(diphenylphosphino)ferrocene displayed a better activity with aryl sulfamates than $\mathrm{IPr} \cdot \mathrm{HCl}_{.}{ }^{45}$

The only mechanistic data available for these $\mathrm{Ni}(\mathrm{COD})_{2} /(\mathrm{S}) \mathrm{IPr} \cdot \mathrm{HCl}(1: 2)$-catalyzed reactions come from control experiments and computational studies conducted on the carbamate amination reaction, that (i) allowed one to rule out a radical based mechanism, and (ii) suggested that, in a manner analogous to the Pd-catalyzed amination, three fundamental steps would occur. These are sequentially: (a) oxidative addition of the electrophile via formation of an initial $\mathrm{NHC}-\mathrm{Ni}\left(\eta^{2}-\right.$ aryl) complex, (b) deprotonation of the coordinated amine after ligand exchange of the carbamate anion with the amine and tert-butoxide, and $(c)$ reductive elimination of the amination product. Additionally, the DFT calculations suggested that the reductive elimination would be the rate-determining step. ${ }^{4346}$ 


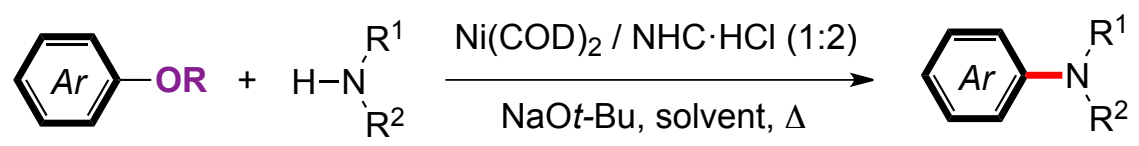

(1.2 - 5.0 equiv.)

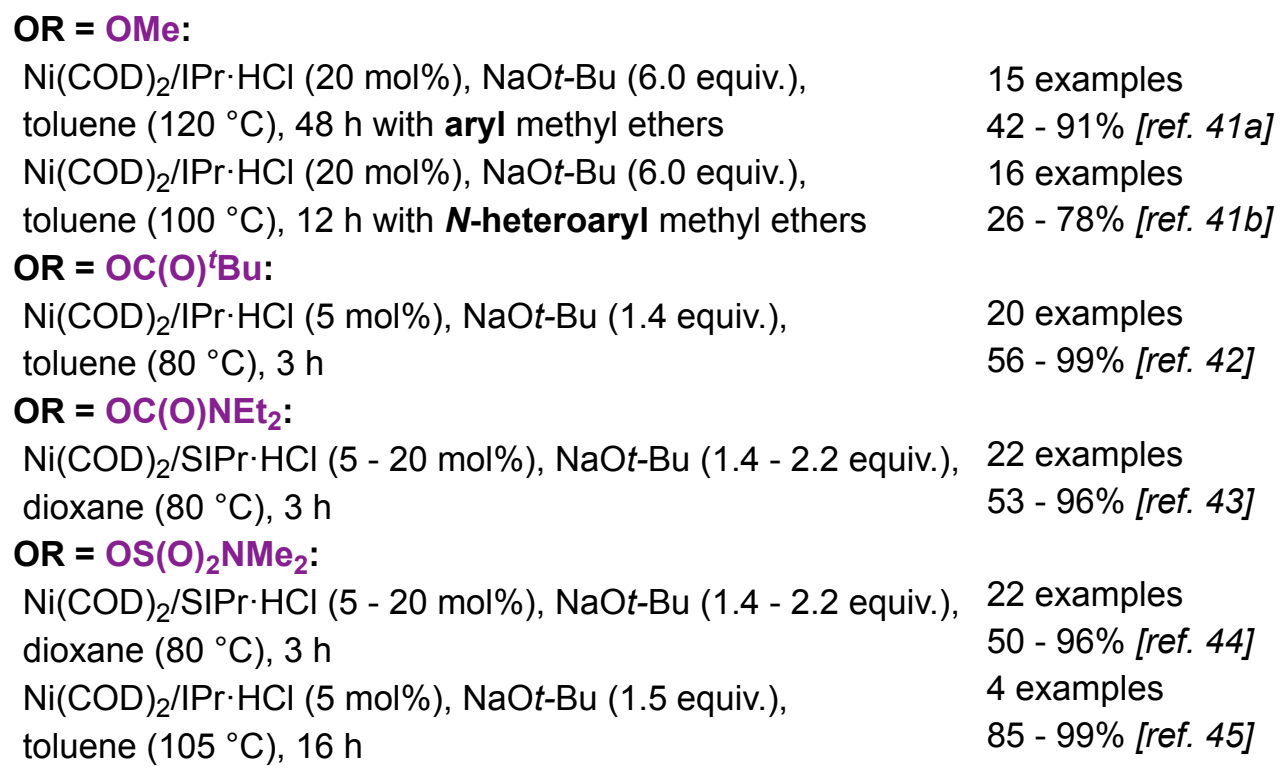

Scheme 10. $\mathrm{Ni}(\mathrm{COD})_{2} / \mathrm{NHC} \cdot \mathrm{HCl}(1: 2)$-Catalyzed Amination of Aryl Methyl Ethers, Pivalates, Carbamates, and Sulfamates ${ }^{4145}$

Whereas in situ generated metal catalysts are often preferred in reason to their facile synthetic use, they can give rise to "cocktail-type systems" with different metal species present in solution, and thus sometimes decreased selectivity. ${ }^{47}$ The use of well-defined $\mathrm{Ni}(\mathrm{NHC})$ complexes addresses this problem, but efforts have up to now been limited to the development of just a few monodentate $\mathrm{Ni}(\mathrm{II})-, \mathrm{Ni}(\mathrm{I})$ - and $\mathrm{Ni}(0)-\mathrm{NHC}$ catalyst precursors.

Matsubara et al. isolated the air-stable 18-electron complex, $\mathrm{Ni}^{\mathrm{n}}(\operatorname{IPr})(\mathrm{acac})_{2}(\mathbf{5})$, from the reaction of $\mathrm{Ni}(\mathrm{acac})_{2}$ with in situ-generated $\operatorname{IPr}^{48}$ Reduction of $\mathbf{5}$ by $\mathrm{NaH}$ with or without an equivalent of $\operatorname{IPr}$ gave $\left[\mathrm{Ni}^{\mathrm{i}}(\operatorname{IPr})_{2}\right](\mathbf{6})$ (Scheme 11). The latter observation allowed the authors to suggest that, in many catalytic reactions with $\mathrm{Ni}$ and $\mathrm{NHC}$ ligands, the in situ-generated $\mathrm{Ni}(0)$ species could have two NHC ligands as a stable resting state. On this basis, they decided to 
compare the activity of $\mathbf{6}$ towards the amination of chlorobenzene with a couple of inactive anilines, with that of Fort's in situ-generated catalytic system from $\mathrm{Ni}(\mathrm{acac})_{2}, \mathrm{SIPr} \cdot \mathrm{HCl}$ and $\mathrm{NaH}^{26}$ (Scheme 12). The fact that slightly better yields were observed with 6 than with Fort's in situgenerated catalyst drove Matsubara et al. to conclude that $\mathbf{6}$ could be closely related to the active species in these reactions. This may indeed seem reasonable but one should note that the NHC ligand used (IPr vs. SIPr) and the amount of base were different in Matsubara's and Fort's protocols (Scheme 12), and this renders any comparison between the two systems hazardous.

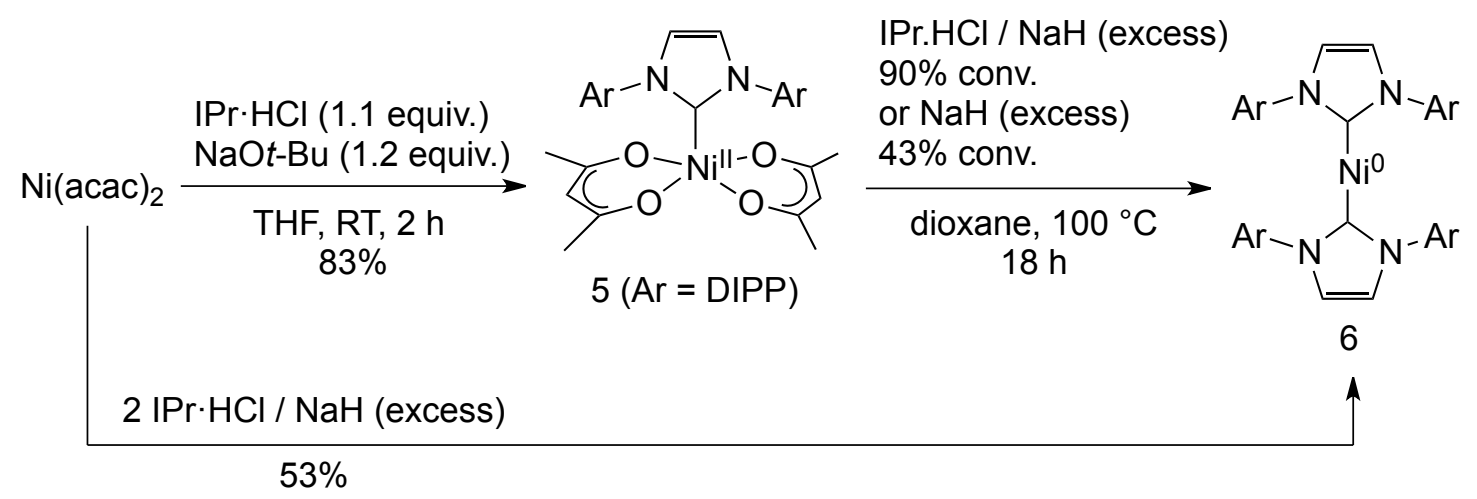

Scheme 11. Synthesis of $\mathrm{Ni}(\operatorname{IPr})(\operatorname{acac})_{2}(5)$ and $\mathrm{Ni}(\operatorname{IPr})_{2}(6)$ from $\mathrm{Ni}(\operatorname{acac})_{2}{ }^{48}$

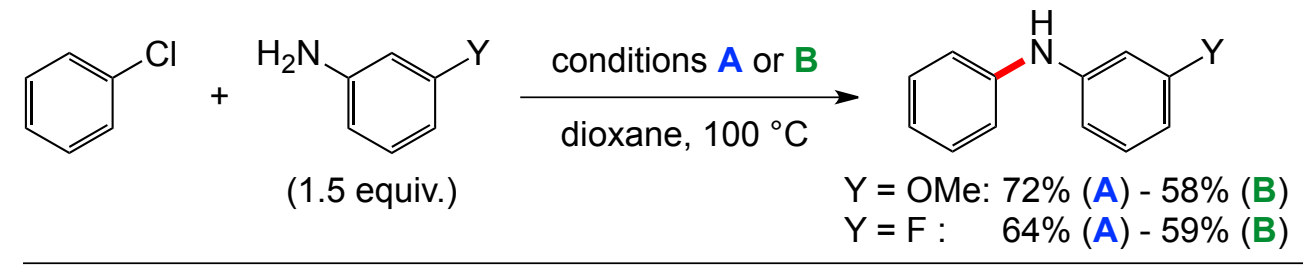

A: 6 (10 mol\%), NaOt-Bu (1.8 equiv.)

B: $\mathrm{Ni}(\mathrm{acac})_{2}(10 \mathrm{~mol} \%), \mathrm{SIPr} . \mathrm{HCl}(20 \mathrm{~mol} \%), \mathrm{NaH}$ (1.6 equiv.), $t-\mathrm{BuOH}$ (1.5 equiv.)

Scheme 12. Catalytic Amination of Chlorobenzene under Matsubara's (A) ${ }^{48}$ and Fort's (B) ${ }^{26}$ Conditions 
In another report, the same group reported the arylation of anilines and morpholine by using the air-stable and easy-to-access nickel(II) complex, $\left[\mathrm{Ni}(\mathrm{IPr})\left(\mathrm{PPh}_{3}\right) \mathrm{Cl}_{2}\right](7)$, in the sole presence of $\mathrm{NaOt}$-Bu, i.e. in the absence of a reductant (Scheme 13) ${ }^{\natural 9} \mathrm{~A}$ rather high catalyst loading of 10 mol\% was required to observe reasonable yields at $100{ }^{\circ} \mathrm{C}$ in toluene, but interestingly, in contrast notably to Fort's system, ${ }^{26}$ the amination of less basic arylamines proceeded more efficiently than that of more basic alkylamines such as morpholine, and the reaction of diphenylamine with 4-bromophenone even produced the triphenylamine quantitatively. Regarding the mechanism, the authors proposed a classical $\mathrm{Ni}(0) / \mathrm{Ni}(\mathrm{II})$ cycle where initial generation of the $\mathrm{Ni}(0)$ complex, $\left[\mathrm{Ni}(\mathrm{IPr})\left(\mathrm{PPh}_{3}\right)\right]$, by reduction of 7 with $\mathrm{NaO} t$-Bu would be followed by (i) oxidative addition of the aryl halide, (ii) transmetalation of the halide with an amide to form an aryl-nickel-amide intermediate, and (iii) reductive elimination. Note that if the nature of the active species is indeed of the $\left[\operatorname{Ni}(\operatorname{IPr})\left(\mathrm{PPh}_{3}\right)\right]$-type, a synergetic action of $\mathrm{IPr}$ and $\mathrm{PPh}_{3}$ similar to that in the $\left[\mathrm{Ni}(\mathrm{Ar}) \mathrm{X}\left(\mathrm{PPh}_{3}\right)_{2}\right] / \mathrm{IPr} \cdot \mathrm{HCl}^{4,37}$ (see Schemes 7 and 8) and $\left[\mathrm{NiCl}_{2}\left(\mathrm{PPh}_{3}\right)_{2}\right] / \mathrm{IPr}_{\mathrm{HCl}} \mathrm{HC}^{\circ}$ (see Scheme 9) systems may be at play here.

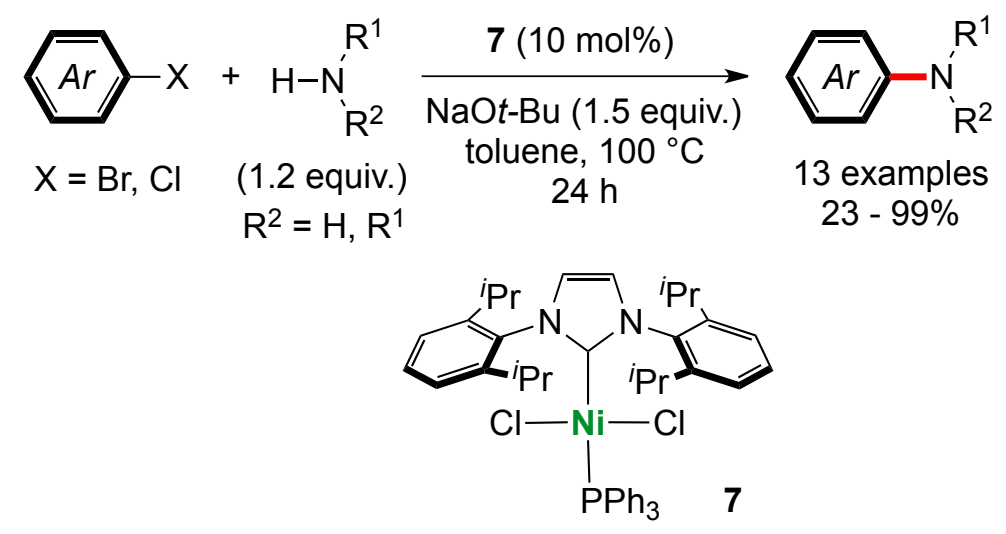

Scheme 13. Amination of Aryl Halides Catalyzed by the mixed PPh/IPr-Nickel(II) Complex $7^{\text {t9 }}$ 
More recently, the same group reported the use of the related mixed phosphine/NHC, but monovalent, complex $\left[\mathrm{Ni}(\mathrm{IPr})\left(\mathrm{PPh}_{3}\right) \mathrm{Cl}\right]$ (9)..$^{50}$ This Y-shaped formally 15-electron nickel(I) complex is formed quantitatively by reaction of 2 equiv. of $\mathrm{PPh}_{3}$ with the dinickel(I) dichloro complex $\mathbf{8}$, with which it is in equilibrium, as shown by the regeneration of the latter from $\mathbf{9}$ in solution in benzene- $d_{6}$ (Scheme 14). In the presence of an excess of $\mathrm{PPh}_{3}, 9$ allowed the coupling of diphenylamine with several aryl halides, in a similar fashion to the divalent complex $\mathbf{7}$, but under milder conditions $\left(5 \mathrm{~mol} \% 9\right.$ at $25-70{ }^{\circ} \mathrm{C} v s .10 \mathrm{~mol} \% 7$ at $\left.100{ }^{\circ} \mathrm{C}\right)$. The enhanced activity of 9 was attributed to both its radical nature (as demonstrated by the easy abstraction of chlorine from $\mathrm{CHCl}_{3}$ to generate 7), which would make the reaction faster than those with zero- and divalent species, and to the easy liberation of phosphine (as shown by its equilibrium with $\mathbf{8}$ ), which would make the unsaturated site easily accessible for the oxidative addition step. On this basis and on that of several reports describing radical mechanisms in nickel and palladium crosscoupling catalysis, , $^{\text {,1 }}$ the authors proposed the $\mathrm{Ni}(\mathrm{I}) / \mathrm{Ni}(\mathrm{III})$ cycle depicted in Scheme 15 , where transmetalation of the nickel(I) halide species with an amide to form a nickel(I) amide intermediate would be followed by oxidative addition of the aryl halide to generate a nickel(III) intermediate, and subsequent reductive elimination to provide the arylamination product and regenerate the initial nickel(I) halide species. 

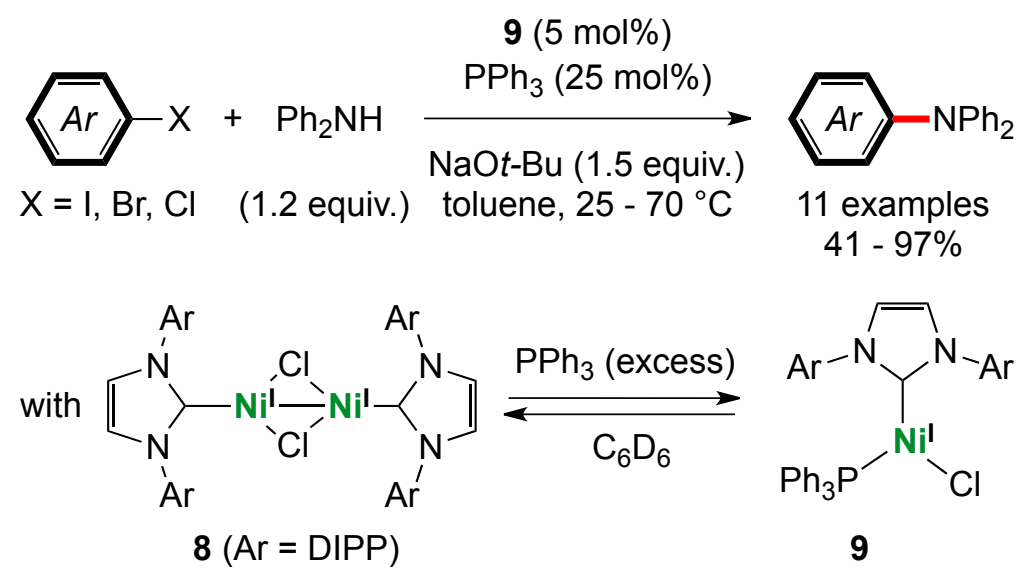

Scheme 14. Diphenylamination of Aryl Halides Catalyzed by the Y-Shaped Monovalent Complex $\mathbf{9}^{\text {s0 }}$

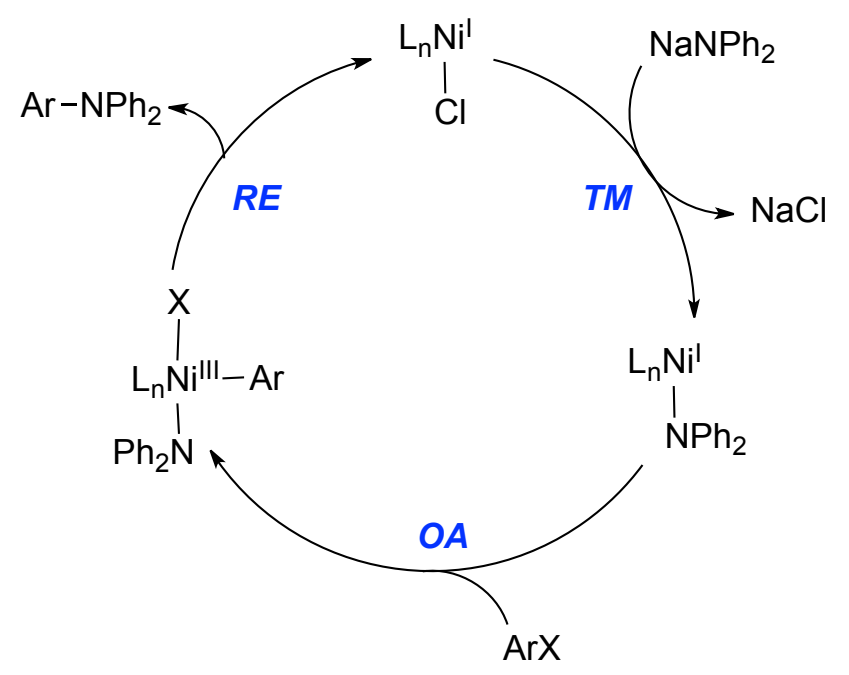

Scheme 15. Proposed Ni(I)/Ni(III) Mechanism for the Arylation of Diphenylamine Catalyzed by the Nickel(I) Complex $9^{50}$

In 2005, Nolan et al. reported the amination of a small number of aryl bromides and chlorides with morpholine catalyzed by $5 \mathrm{~mol} \%$ of four half-sandwich complexes of general formula [Ni(NHC)ClCp] (10) bearing IMes (a), IPr (b), SIMes (c) and SIPr (d) ligands in the sole presence of $\mathrm{KO} t$-Bu (2 equiv.). Relatively low yields were however observed in 1,4-dioxane at 
$105{ }^{\circ} \mathrm{C}$, in particular with aryl chlorides..$^{52}$ The authors suspected that the reasons for this moderate activity could arise from the challenging reduction of the well-defined $\mathrm{Ni}(\mathrm{II})-\mathrm{NHC}$ precatalysts $\mathbf{1 0 a - d}$ to a catalytically active $\mathrm{Ni}(0)$ species, and from the difficulty in labilizing the $\mathrm{Cp}$ ligand. Hence, they recently hypothesized that the use of bulkier, yet flexible, NHC ligands could: (i) increase the steric pressure on the $\mathrm{Cp}$ ligand and hence favor its decoordination during the reduction process, (ii) improve the stability of the $\mathrm{Ni}(0)-\mathrm{NHC}$ active species, and thus enhance its catalytic performance, and (iii) still allow the coordination of incoming substrates.5. Following this reasoning, four new complexes $\mathbf{1 0}$ bearing the bulky yet flexible IPent (e), IPr* $(\mathbf{f}), \operatorname{IPr}^{* \text { то }}(\mathbf{g})$ and $\operatorname{IPr}^{*_{\text {оме }}}(\mathbf{h})$ ligands were synthesized and their activity studied in the amination of aryl chlorides. All new complexes, except 10e, showed better results than 10a-d, and 10h, in particular, proved able to catalyze with good efficiency the coupling of a few cyclic secondary amines and anilines with electron-rich, -neutral and -poor chloroaryls under slightly modified reaction conditions (Scheme 16). Sterically hindered aryl chlorides however proved incompatible with this catalytic system, underlying its limitations.

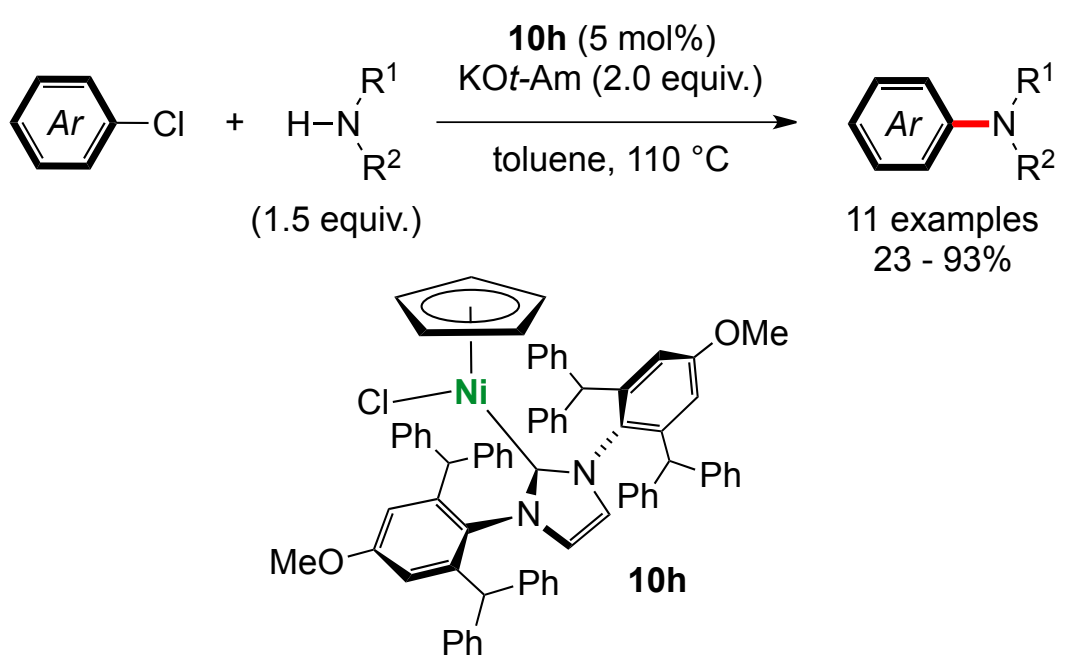


Scheme 16. Amination of Aryl Chlorides Catalyzed by Complex 10h Bearing the Bulky yet Flexible IPr*оме Ligand ${ }^{\text {s3 }}$

A notable improvement was achieved by using the related 16-electron $\pi$-allyl nickel complex [Ni(IPr)(allyl)Cl] (11), which allowed the first examples of nickel-catalyzed Buchwald-Hartwig couplings that operate at room temperature..$^{54}$ In particular, the amination of electron-neutral, -rich and -poor para-substituted chloroaryls with morpholine, and that of $\mathrm{N}$-containing heteroaromatic chlorides with secondary amines and anilines proceeded smoothly at room temperature in the presence of 2.5 to $5 \mathrm{~mol} \%$ of $\mathbf{1 1}$ and of $\mathrm{NaOt}$-Bu to give the cross-coupling products in good to excellent yields (Scheme 17). This unprecedented activity was tentatively explained by the presence of the allyl moiety in $\mathbf{1 1}$, which would help reducing $\mathrm{Ni}(\mathrm{II})$ to $\mathrm{Ni}(0)$, probably in a way similar to that proposed for Pd(II) analogues..$^{55}$

More recently, the replacement of the IPr ligand of $\mathbf{1 1}$ by the bulkier IPr*ove - similarly to what was carried out with the Cp complexes $\mathbf{1 0}$ - allowed a decrease of the catalyst loading to 1 to 2 mol\%, but the reactions were performed at temperatures ranging from 60 to $100{ }^{\circ} \mathrm{C} .{ }^{56}$

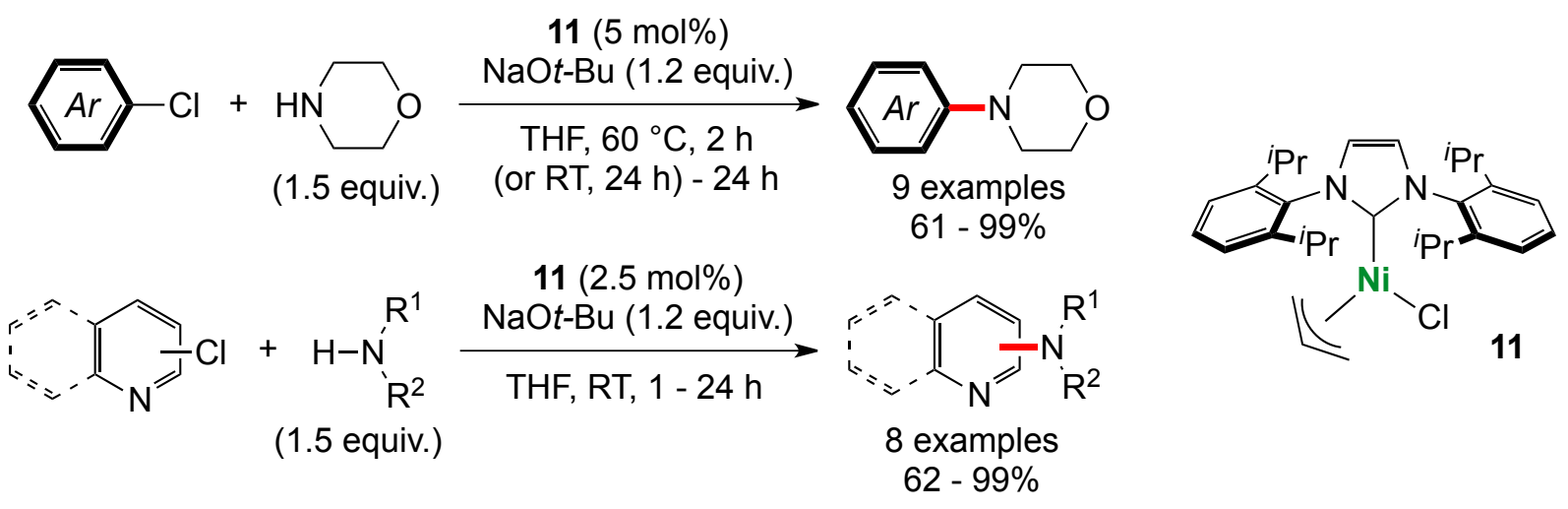

Scheme 17. Amination of Aryl and Heteroaryl Chlorides Catalyzed by $\mathbf{1 1}^{\text {s4 }}$ 
Two interesting last reports from Belderrain and Nicasio described the catalytic activity of the bis-styrene IPr-Ni(0) complex 12 in the coupling of aryl tosylates with secondary cyclic amines and anilines, ${ }^{57}$ and of indoles and carbazoles with (hetero)aryl chlorides (Scheme 18). ${ }^{58}$ The aminations of aryl tosylates were achieved quickly in 1,4-dioxane at $110{ }^{\circ} \mathrm{C}$ in the presence of 5 mol\% 12 and 1.5 equiv. of $\mathrm{LiOt}$-Bu and also worked well with ortho- and $\mathrm{N}$-substituted anilines..$^{57}$ Nevertheless, the reaction rate depended on the electronic nature of the substituents on the electrophile, and electron-rich tosylates required longer reaction times $(3-5 \mathrm{~h} v s .15 \mathrm{~min}-1$ h for electron-neutral and electron-poor tosylates). Furthermore, the Ni(II) complex 11 could also catalyze the coupling of phenyl tosylate with morpholine, but with a greatly reduced efficiency compared to 12: only $40 \%$ conversion were observed in 15 min with $\mathbf{1 1}$, compared to $90 \%$ with 12.

The challenging couplings of indoles and carbazoles with (hetero)aryl chlorides ${ }^{58}$ were achieved in fairly short reaction times $(2 \mathrm{~h})$ as well, in the presence of a catalyst loading varying between $5 \mathrm{~mol} \%$ for the coupling of aryl chlorides and $10 \mathrm{~mol} \%$ for that $\mathrm{N}$-containing heteroaryl chlorides (Scheme 18). No competing C-arylation process was observed.

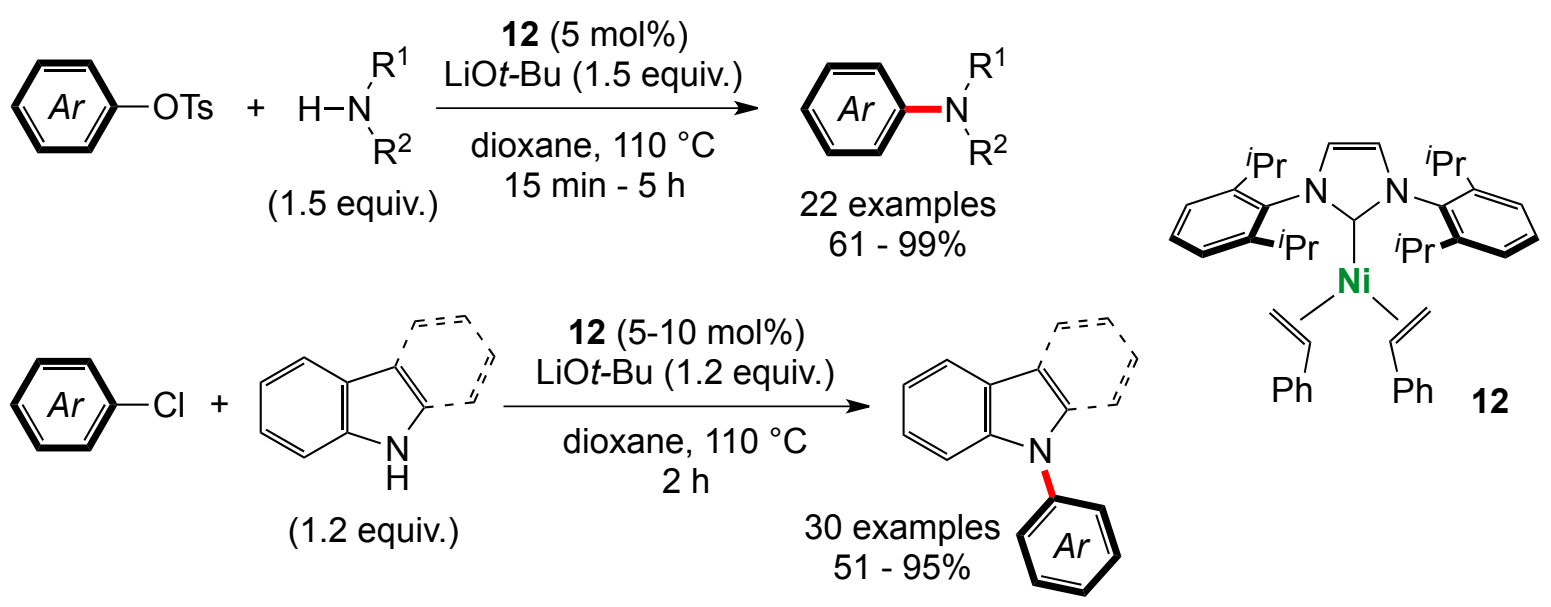


Scheme 18. Coupling of Secondary Cyclic Amines and Anilines with Aryl Tosylates and of Indoles and Carbazoles with (Hetero)Aryl Chlorides Catalyzed by $\mathbf{1 2}^{5 / 5 s}$

\subsubsection{Dehydrogenative Cross-Coupling of Aldehydes and Amines. Very recently, Dong et al.} reported an unprecedented nickel-catalyzed dehydrogenative cross-coupling method that allows the direct transformation of aldehydes into either esters (see Section 4) or amides. ${ }^{59}$ Thus, in the presence of $\alpha, \alpha, \alpha$-trifluoroacetophenone as a mild organic oxidant, a 1:1.1 combination of $\mathrm{Ni}(\mathrm{COD})_{2}$ and IPr was shown to efficiently couple aromatic and aliphatic aldehydes with anilines under mild conditions (14 examples - Scheme 19). Of note, electron-donating and -withdrawing substituents were well tolerated on both the electrophile and the nucleophile. In addition, hindered anilines were also shown to be suitable coupling partners, including those with ortho substituents or substituents on the nitrogen atom. Nevertheless, under these conditions, the reactions with amines as nucleophiles were plagued by condensation side products, and $\alpha, \alpha, \alpha-$ trifluoroacetophenone and IPr had to be replaced by a second equivalent of the aldehyde (as the hydrogen acceptor) and $\mathrm{I} t \mathrm{Bu}$ (as the ligand) to suppress condensation of the amine with respectively the ketone and the aldehyde (Scheme 19). Under these slightly modified conditions, primary alkyl amines, benzylic amines or cyclic secondary amines were efficiently coupled with aromatic aldehydes (7 examples). Mechanistic data support a catalytic cycle involving oxidative addition of the aldehyde $\mathrm{C}-\mathrm{H}$ bond onto an electron-deficient nickel(0) center (see Section 4). 


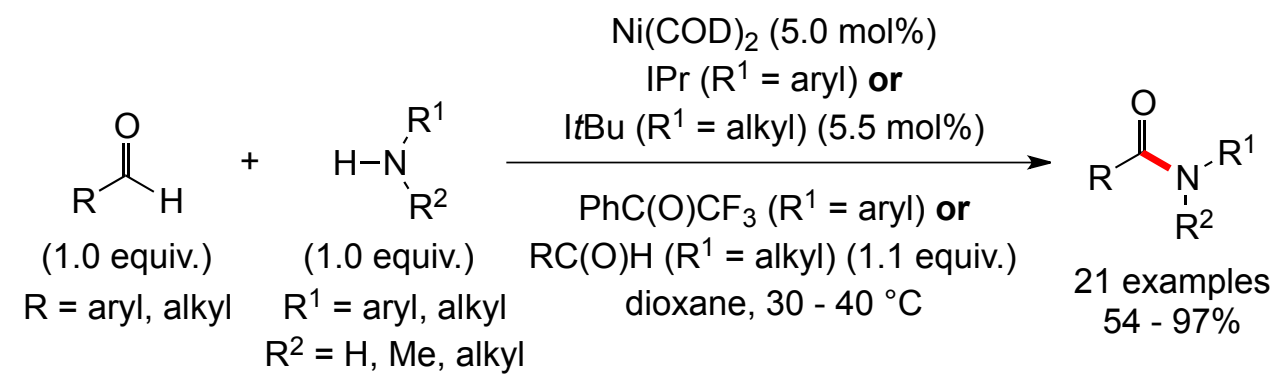

Scheme 19. Dehydrogenative Cross-Coupling of Aldehydes and Amines ${ }^{59}$

\subsection{N-H Bond Additions Across C-C Multiple Bonds}

2.2.1. Hydroamination of Olefins. Although the hydroamination of olefins or alkynes provides an attractive $100 \%$ atom-economic route from inexpensive and readily available starting materials to nitrogen containing chemical feedstock that are of interest to the pharmaceutical and agrochemical industries, the use of inexpensive first row late transition metal-based catalysts in these reactions is still in its infancy ${ }_{{ }^{60}}$ Nickel catalysts, in particular, have been rarely used, and to our knowledge, the 1,2,4-triazole based $\mathrm{NHC}$ complexes $\mathbf{1 3 a}, \mathbf{b}$ are the only $\mathrm{Ni}(\mathrm{NHC})$ species that have been reported to date to be active in the hydroamination reactions of a small number of cyclic and acyclic secondary amines with activated alkenes (Scheme 20). ${ }^{6}$ Interestingly, these nickel complexes exhibited superior activity than their palladium homologues. This was attributed to their greater Lewis acidity, as both Mulliken and natural charge analyses showed the nickel center in 13a and 13b to be electron poorer than the palladium center in their palladium homologues. In addition, the observation by mass spectrometry of an olefin adduct obtained when the Pd homologue of 13a was treated with acrylonitrile in the presence of AgOTf allowed the authors to propose a mechanism in which activation of the olefin by coordination to the metal center would be followed by an anti-Markovnikov attack of the amine to give a metal bound 2- 
aminoalkyl intermediate that would finally release the product after protonolysis. No such evidence was however given for the nickel-catalyzed reaction

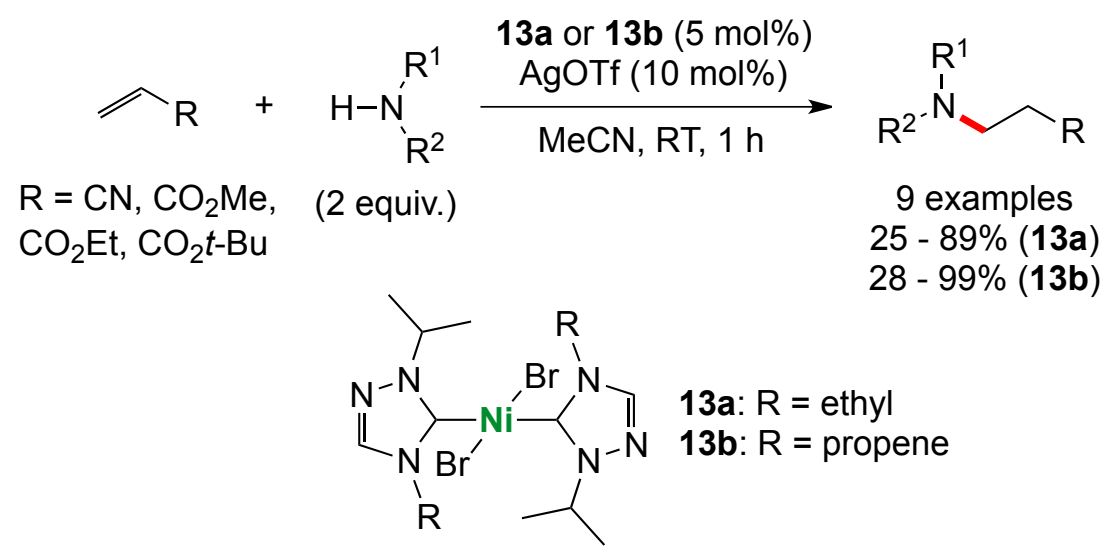

Scheme 20. Hydroamination of Activated Olefins Catalyzed by Complexes 13a, $\mathbf{b}^{61}$

2.2.2. Hydroimination of Alkynes. The addition of an imine $\mathrm{N}-\mathrm{H}$ bond across an unactivated $\mathrm{C}-\mathrm{C}$ multiple bond of an alkene or an alkyne would provide a convenient and atom-economic route to ubiquitous $\mathrm{N}$-substituted imines. Nevertheless, such hydroimination had never been described until very recently, when a $\mathrm{Ni}(\mathrm{COD})_{2} / \operatorname{IPr}(1: 2.2)$ combination was reported to catalyze the formal anti addition of aromatic $\mathrm{N}-\mathrm{H}$ ketimines onto internal alkynes in the presence of $\mathrm{Cs}_{2} \mathrm{CO}_{3}$ as an additive (Scheme 21). ${ }^{62}$ Remarkably, the reaction is highly chemoselective and leads to azadienes in good to high yields with a relatively broad range of diaryl and aryl,alkyl N-H ketimines and symmetrical diarylacetylenes. Moreover, all of the azadiene products were detected and isolated as a single isomer with a (3Z)-2-aza-1,3-butadiene structure. Symmetrical dialkylacetylenes were significantly less reactive and required an excess of ketimine to give moderate yields. 


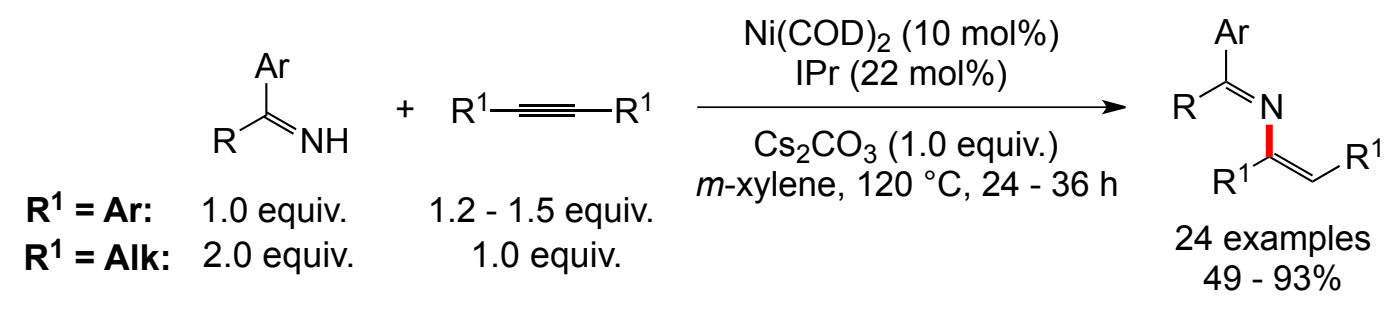

Scheme 21. Hydroimination of Alkynes Catalyzed by a Ni(COD) $)_{2} / \operatorname{IPr}(1: 2.2)$ Combination $^{22}$

Based on the stereoselectivity of the reaction and on deuterium-labeling experiments, which suggested that the hydroimination path might involve an intermolecular proton transfer between reactive intermediates and the reaction medium, the authors proposed a mechanism in which the reaction would go through: (i) formation of a $\mathrm{Ni}(0)$-alkyne $\pi$-complex, (ii) stereospecific antiattack of this complex by the imine nucleophile, and (iii) proton transfer from the resulting iminium to the nickel-alkenyl linkage via the reaction medium (Scheme $22-\mathrm{A}$ ). Interestingly, the independently synthesized nickel( $(0) \eta^{1}, \eta^{2}$-bis-imine complex 14 displayed improved activity compared to the $\mathrm{Ni}(\mathrm{COD})_{2} / \mathrm{IPr}(1: 2.2)$ combination (Scheme $22-\mathrm{B}$ ), suggesting that such a bisimine complex may act as activated catalytic precursor and could yield a $\mathrm{Ni}(0)$-alkyne $\pi$ complex similar to that proposed in the catalytic cycle by facile $\pi$-imine replacement with the alkyne while keeping the $\sigma$-imine ligand intact. 
(A) Proposed catalytic cycle

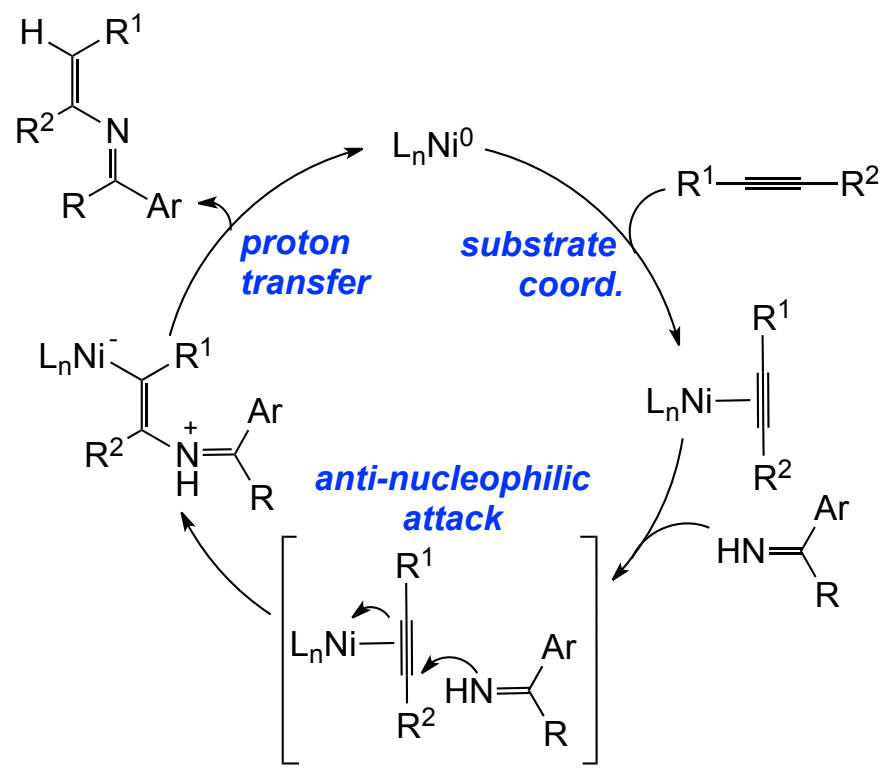

(B) Catalytic activity of 14

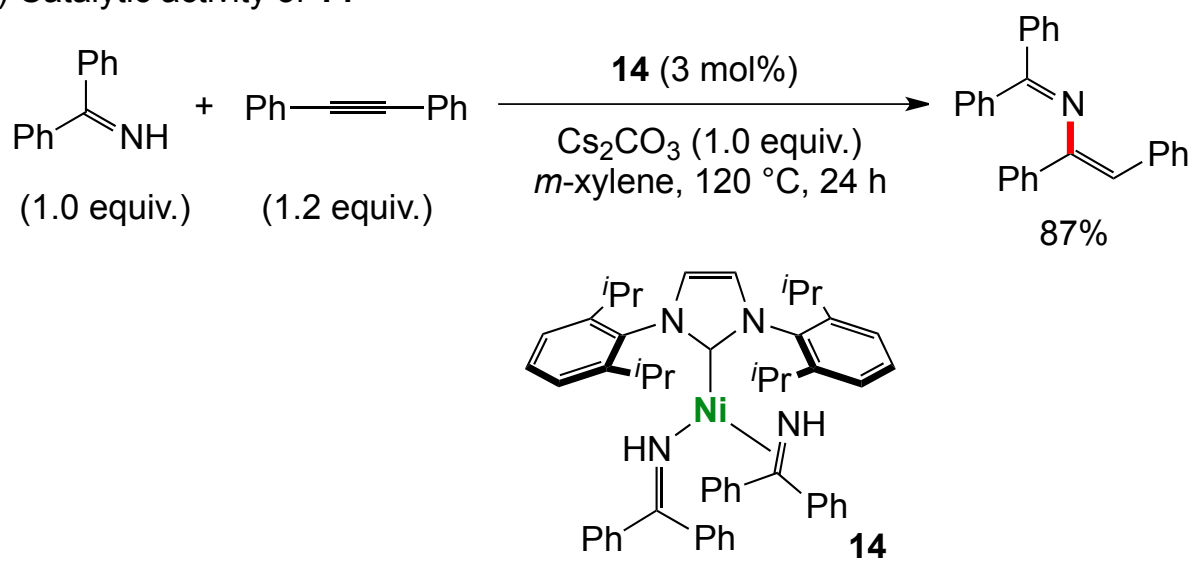

Scheme 22. Proposed Mechanism for the Hydroimination of Alkynes (A) and Catalytic Activity of the $\eta^{1}, \eta^{2}$-bis-Imine Complex $14(\mathrm{~B})^{62}$

2.2.3. One-Step Indoline Synthesis from Iodoacetanilides and Alkenes. The addition of a photoredox catalyst to a nickel catalyst can allow controlled access to multiple oxidation states in a single catalytic cycle and thus give access to novel chemistry, as demonstrated by the recent simultaneous reports of Molander and MacMillan. ${ }^{16}$ Such strategy has been recently used to develop the first general annulation reaction of iodoanilines and terminal alkenes. ${ }^{63}$ Thus, the 
combination of $\mathrm{Ni}(\mathrm{COD})_{2} / \mathrm{IPr}(1: 1)$ with $\left[\mathrm{Ru}(\mathrm{bpy})_{3}\right]\left(\mathrm{PF}_{6}\right)_{2}$ under blue LED irradiation allowed the preparation of a relatively large variety of 3-substituted indolines from 2-iodoacetanilides and aliphatic and styrenyl olefins with very high regio- and chemoselectivities over 2-substituted indolines and Heck products (Scheme 23).

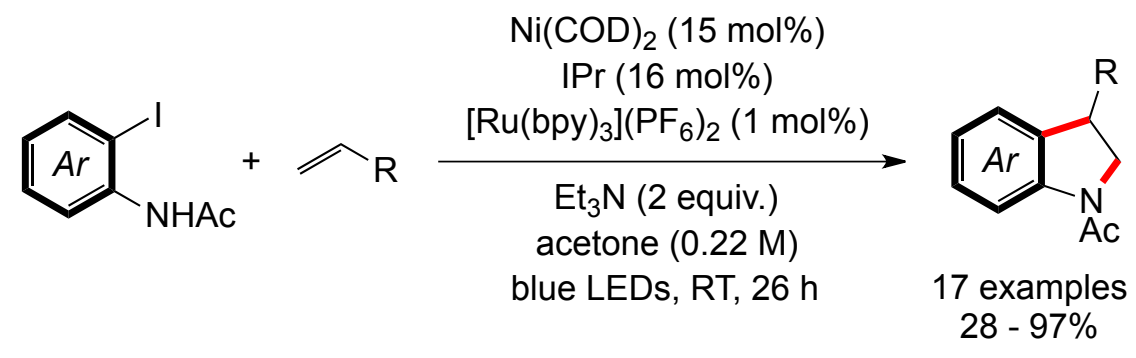

Scheme 23. Nickel/Photoredox-Catalyzed Synthesis of Indolines ${ }^{63}$

Mechanistic investigations allowed the authors to propose the mechanism depicted in Scheme 24 , where oxidation of the migratory insertion complex to $\mathrm{Ni}$ (III) by the photoredox catalyst would be necessary to allow the difficult $\mathrm{C}-\mathrm{N}$ bond forming reductive elimination, that produces the annulation product and a $\mathrm{Ni}(\mathrm{I})$ complex, which would then be reduced to $\mathrm{Ni}(0)$ prior to oxidative addition of the 2-iodoacetanilide. 


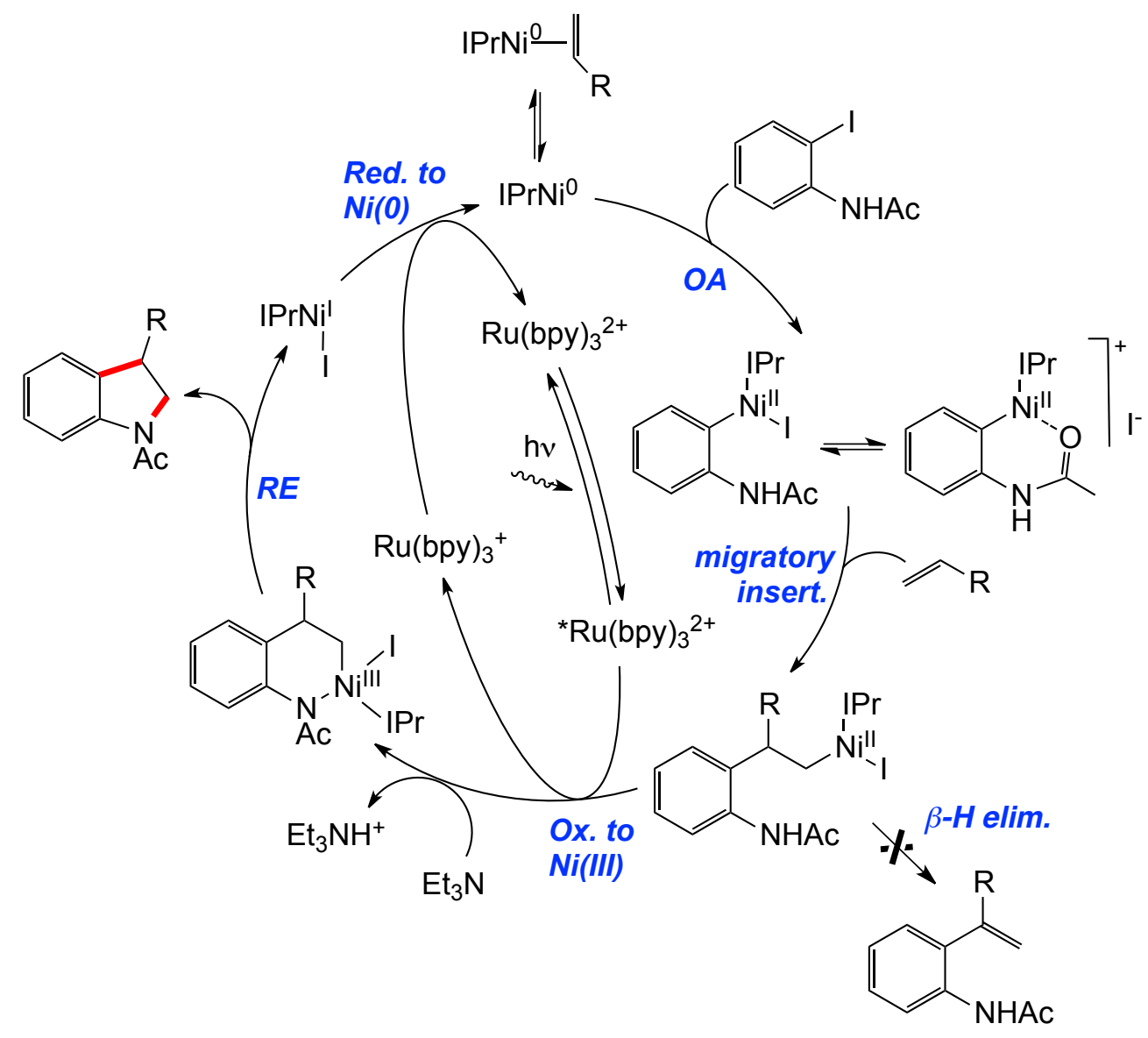

Scheme 24. Proposed Mechanism for the Nickel/Photoredox-Catalyzed Synthesis of Indolines ${ }^{63}$

\section{CARBON-SULFUR BOND FORMATION}

\subsection{Cross-Coupling Methodologies: The Thiolation of Aryl Halides}

$\mathrm{C}-\mathrm{S}$ couplings have been much less studied than $\mathrm{C}-\mathrm{N}$ couplings, and only a very limited number of $\mathrm{Ni}(\mathrm{NHC})$ systems have been shown to promote the formation of $\mathrm{C}-\mathrm{S}$ bonds between thiol derivatives and electrophiles.

The first example was described in 2007 when the presumed bis-NHC-nickel species, Ni(IBn) (15), which was prepared beforehand by reaction of $\mathrm{Ni}(\mathrm{COD})_{2}$ with 2 equivalents of $\mathrm{IBn} \cdot \mathrm{HBr}$ in the presence of 2 equivalents of $\mathrm{KO} t$ - $\mathrm{Bu}$, was reported to efficiently couple thiophenol with a 
small array of aryl iodides and bromides in DMF at high temperature (Scheme 25). ${ }^{64} \mathrm{~A}$ good yield (78\%) was also observed for the coupling of 4-bromotoluene with thiohexane, but this was the only reported example with an alkyl thiol. No mechanistic data were given, but the authors assumed that the bis-NHC-nickel species $\mathbf{1 5}$ undergoes an oxidative addition/reductive elimination cycle similar to that observed with palladium organophosphane catalysts..s

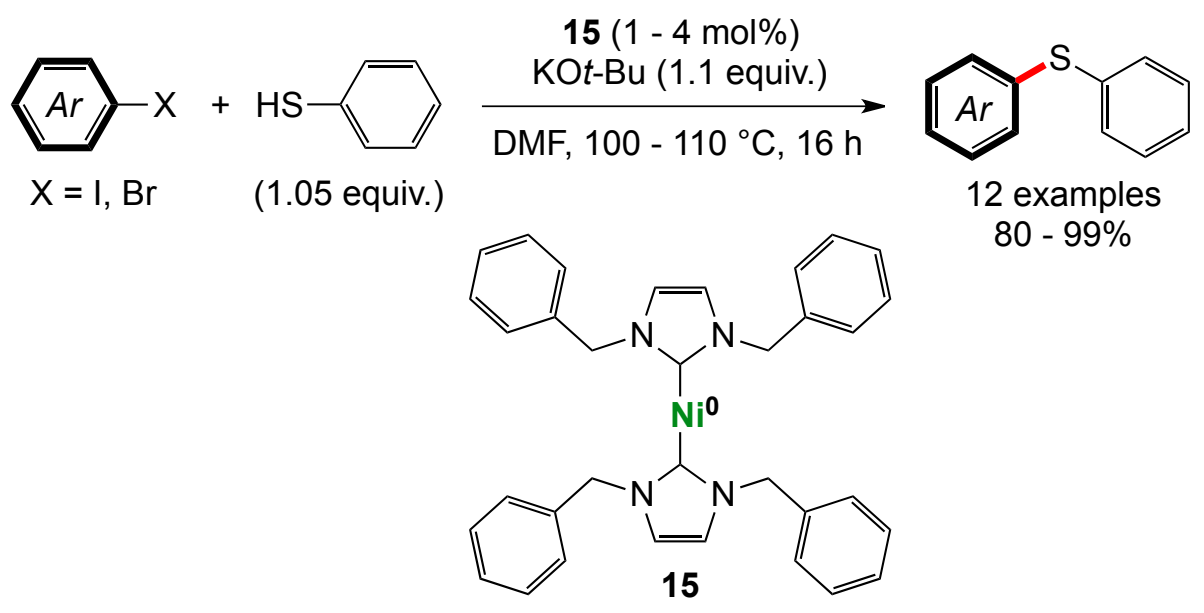

Scheme 25. First Ni(NHC)-Catalyzed Thiolation of Aryl Iodides and Bromides with Thiophenol ${ }^{\star}$

More recently, the readily available and easy-to-handle $\mathrm{Ni}(\mathrm{OAc})_{2}$ was reported to catalyze the C-S coupling of a large array of phenyl-, benzyl- and alkylthiols with aryl iodides, bromides and electron-deficient aryl chlorides in the presence of IPr and $\mathrm{KO} t$-Bu (Scheme 26) ${ }_{{ }^{66}}$ Curiously, the influence of the Ni/IPr ratio was relatively insignificant, and a 1:0.5 ratio gave similar results than a 1:1 ratio, but the required catalyst loading was much higher than with the in situ generated bis-NHC species 15. No mechanistic information was reported. 


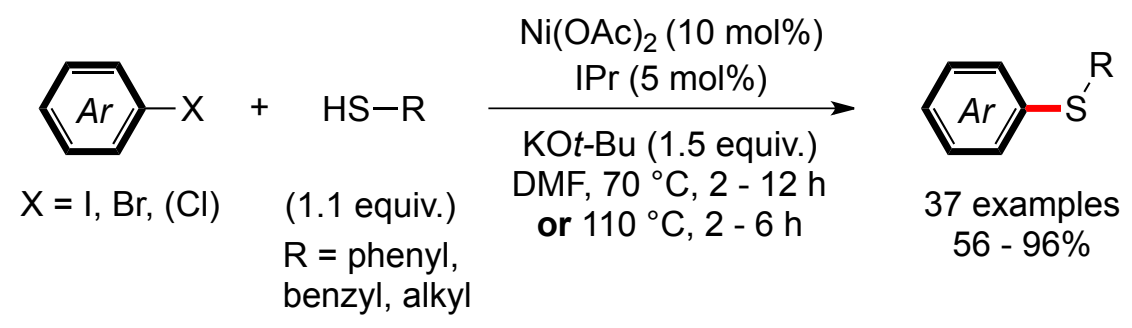

Scheme 26. Aryl-, Benzyl- and Alkylthiolation of Haloarenes Catalyzed by $\mathrm{Ni}(\mathrm{OAc})_{2} / \operatorname{IPr}(2: 1)^{66}$

The use of well-defined $\mathrm{Ni}(\mathrm{NHC})$ complexes have up to now been limited to the development of only one type of Ni(II)-NHC catalyst precursors. Thus, the $\pi$-allyl nickel(II) complex 11, which proved highly active in aryl amination reactions (vide supra - Scheme 17), also showed interesting activities in the thiolation of a few aryl iodides and bromides with a small array of thioaryls in the presence of $\mathrm{NaO} t$-Bu as the sole additive (Scheme 27). ${ }^{54}$ In general, yields did not vary significantly by changing the nature of the substituent both in the aryl iodide and in the thioaryl, and these couplings were achieved efficiently with catalyst loadings of 1 to $3 \mathrm{~mol} \%$. Aryl bromides, however, required a catalyst loading of $5 \mathrm{~mol} \%$ to observe satisfying yields, and only $30 \%$ yield was observed in the case of the coupling of thiophenol with 4-chlorotoluene. Again, a slight improvement was obtained by replacing the IPr ligand of $\mathbf{1 1}$ by the bulkier IPr*oмe ligand. ${ }^{56}$ Thus, the coupling of iodoarenes could be achieved with a catalyst loading of 0.5 to 1 mol\%, and that of bromoarenes with a catalyst loading of 1 to 2 mol\%. Surprisingly, however, no conversion was observed for the coupling of thiophenol with 4-chlorotoluene.

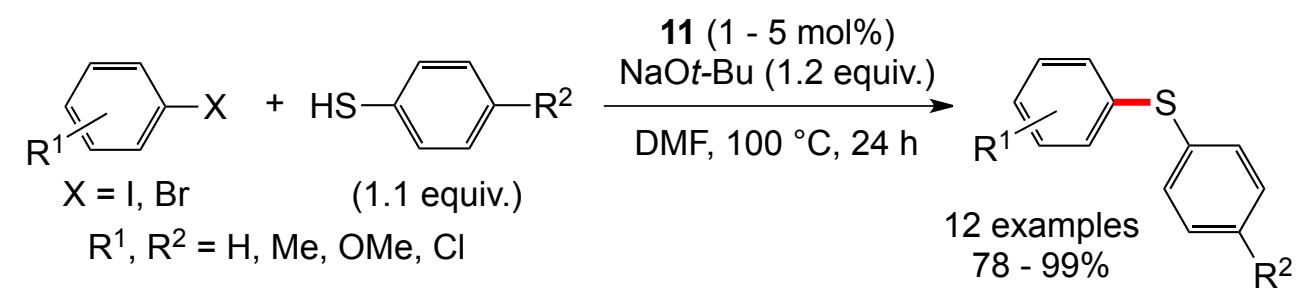

Scheme 27. Arylthiolation of Bromo- and Iodo-Arenes Catalyzed by $\mathbf{1 1}^{54}$ 
Finally, the recyclable Ni(NHC) species 16 - derived from 1-[3-(silyloxy)propyl]-3-picolylimidazolinium chloride immobilized on magnetite/silica nanoparticles and $\mathrm{Ni}(\mathrm{acac})_{2}$, and of the plausible structure that is depicted in Scheme 28 - has been applied in the arylthiolation of a few aryl iodides with a relatively good efficiency ( 7 examples, 89 - 95\% yield with 10 mol\% 16 in DMF at $100{ }^{\circ} \mathrm{C}$ for $10-12 \mathrm{~h}$ ). Interestingly, 16 could be easily recovered with an external magnet after each run, and has been used up to three times without notable decrease of activity.

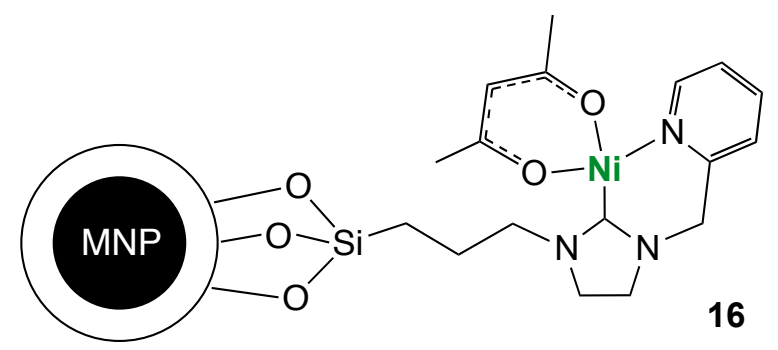

Scheme 28. Plausible Structure of the Recyclable Ni(NHC) Species $\mathbf{1 6}$

\subsection{Other Methodologies: The Hydrothiolation of Alkynes}

Although sulfur-hydrogen bond addition to alkynes results in vinyl sulfides with a $100 \%$ atom efficiency, the use of nickel-based catalysts in these reactions is still in its infancy, ${ }^{\text {sb }}$ and we are aware of only one $\mathrm{Ni}(\mathrm{NHC})$-catalyzed example. Thus, the $[\mathrm{Ni}(\mathrm{NHC}) \mathrm{ClCp}]$ complexes 10a-d were shown to catalyze the regioselective Markovnikov-type addition of a single S-H bond of arylthiols to alkynes.8 ${ }^{68}$ In particular, the IMes complex 10a allowed the hydrothiolation of a few terminal alkynes to be performed with high regioselectivity (up to 31:1) and in generally good yields in the presence of only 1 mol\% catalyst and $\mathrm{NEt}_{3}$ under solvent free conditions (Scheme 29). An excess of thioaryl, however, needed to be present during the course of the reaction, to 
achieve good yield and selectivity: this drove the authors to add the alkyne in three portions in order to avoid using an excess of alkyne.

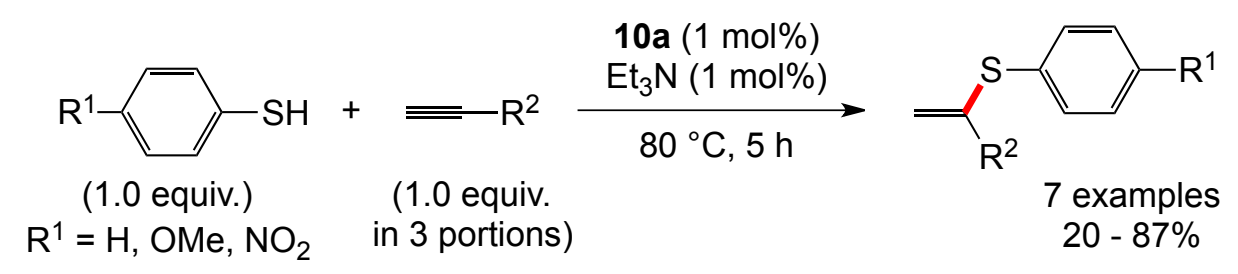

Scheme 29. Hydrothiolation of Alkynes Catalyzed by Complex 10a $\mathbf{a}^{68}$

Mechanistic investigations revealed that the thiol complexes 17, which were formed quantitatively by stoichiometric reactions of complex $\mathbf{1 0 a}$ with arylthiols in the presence of $\mathrm{NEt}_{3}$, are catalytically active in the absence of triethylamine. On this basis, the authors proposed the catalytic cycle depicted in Scheme 30, in which complexes $\mathbf{1 7}$ would insert an alkyne into the $\mathrm{Ni}-\mathrm{S}$ bond to afford an unstable thioalkenyl intermediate that would then be trapped by another equivalent of arylthiol to yield the desired vinylsulfide and regenerate the active species. 


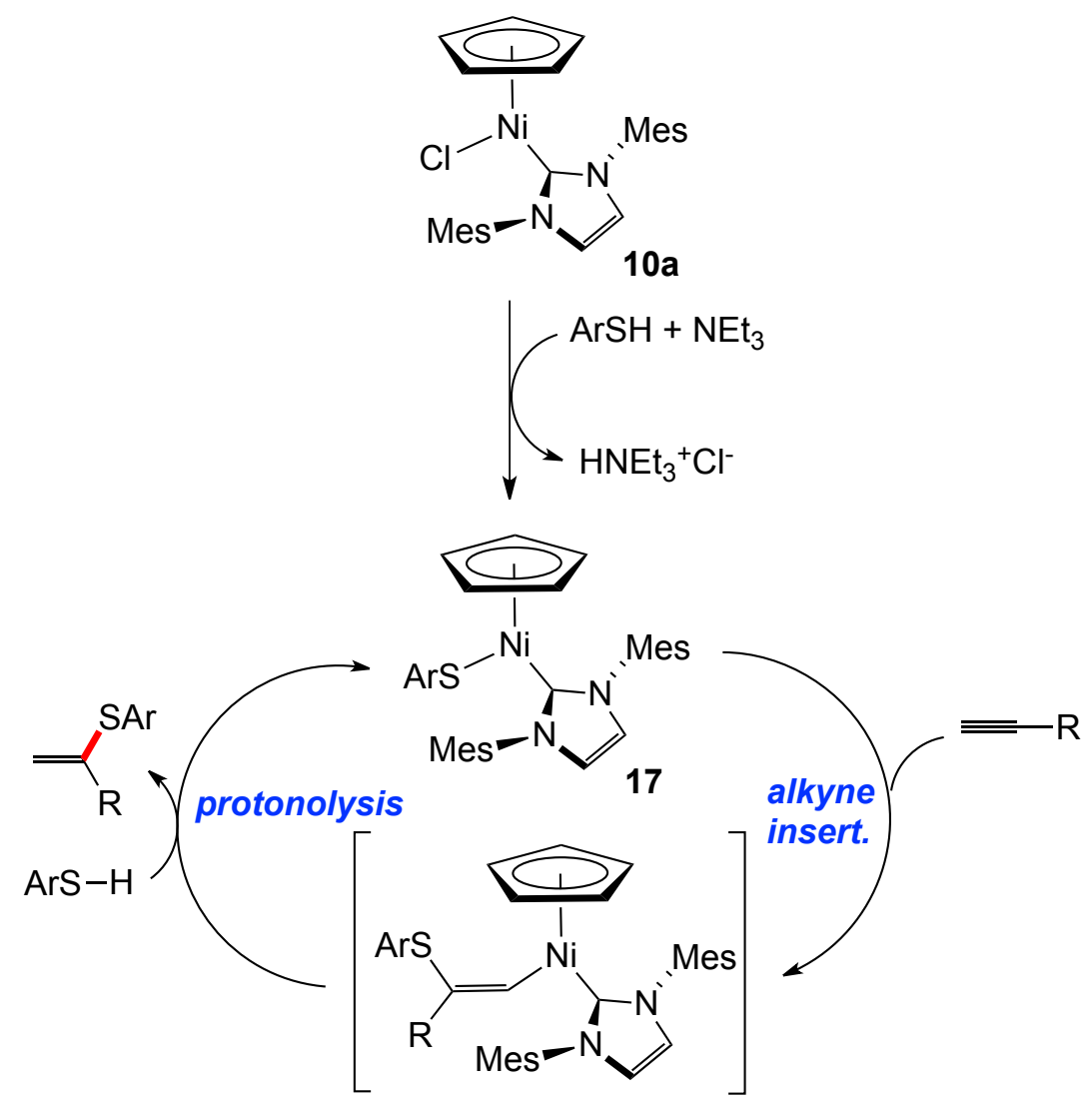

Scheme 30. Proposed Catalytic Cycle for the Hydrothiolation of Alkynes ${ }^{68}$

\section{CARBON-OXYGEN BOND FORMATION}

Examples of $\mathrm{Ni}(\mathrm{NHC})$-catalyzed Carbon-Oxygen coupling reactions are extremely rare and are almost exclusively limited to the Tishchenko reaction, which allows the $100 \%$ atomeconomic dimerization of aldehydes to produce an ester. ${ }^{6}$ Thus, a $\mathrm{Ni}(\mathrm{COD})_{2} / \mathrm{IPrCl}(1: 1)$ combination was shown by Ogoshi and coworkers to promote the homo-dimerization of a variety of aryl and primary, secondary and tertiary alkyl aldehydes in toluene at 60 to $80{ }^{\circ} \mathrm{C}$ with a great efficiency (Scheme 31). ${ }^{70}$ In most cases, catalyst loadings varied between 1 and 3 mol\%, reaction times between 1 and $4 \mathrm{~h}$, and yields between 82 and 99\%. The homo-dimerization of heteroaryl 
aldehydes and of sterically encumbered or electron-poor aryl aldehydes, however, gave either lower yields or required higher catalyst loadings or longer reaction times.

Monitoring the reaction of 2-naphtaldehyde in the presence of $20 \mathrm{~mol} \% \mathrm{Ni}(\mathrm{COD})_{2} / \mathrm{IPrCl}$ by ${ }^{\mathrm{H}} \mathrm{H}$ NMR spectroscopy at $-60{ }^{\circ} \mathrm{C}$ allowed the observation of the formation of a $\mathrm{Ni}(0)$ - $\mathrm{IPrCl}$ complex bearing two $\eta^{2}$-coordinated molecules of aldehyde, which most probably acts as a key intermediate, as warming up the reaction mixture to $25^{\circ} \mathrm{C}$ quantitatively gave the corresponding homo-dimer ester (Scheme 31).
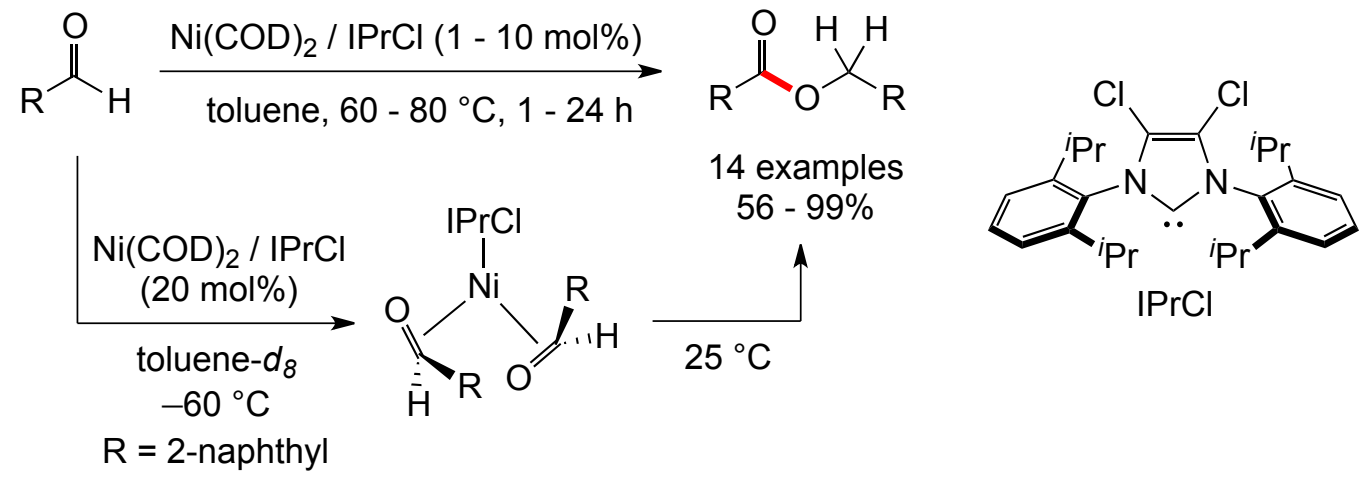

Scheme 31. $\mathrm{Ni}(\mathrm{COD})_{2} / \operatorname{IPrCl}(1: 1)$-Catalyzed Tishchenko Reaction ${ }^{70}$

A simple change of ligand from $\mathrm{IPrCl}$ to SIPr remarkably allowed the same authors to report the first highly selective cross-Tishchenko reaction of aliphatic aldehydes with aryl aldehydes (Scheme 32). ${ }^{n}$ Except for the reaction of cyclohexanecarbaldehyde with the sterically congested 2,4,6-trimethylbenzaldehyde, which resulted in a decreased selectivity (64\%) and yield (57\%), the cross-coupled ester, alkylCO $\mathrm{CH}_{2} \mathrm{Ar}$, was always obtained predominantly from the four possible esters with an excellent selectivity $(87->99 \%)$ and a good to high yield $(61-94 \%)$. 


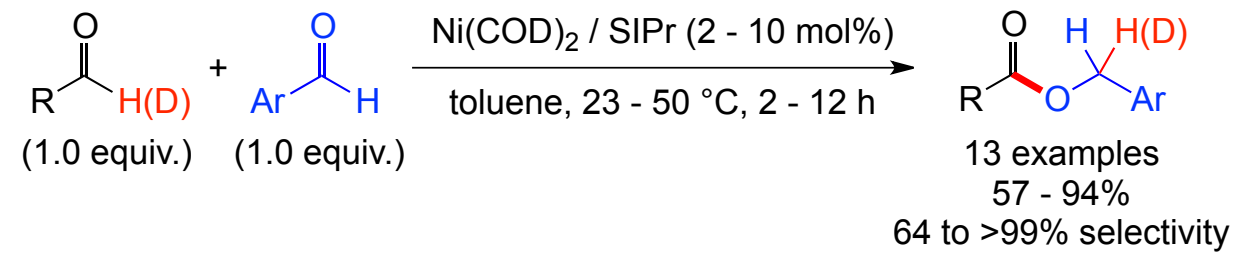

Scheme 32. Ni(COD)//SIPr (1:1)-Catalyzed Cross-Tishchenko Reaction" ${ }^{1}$

'H NMR monitoring of the reaction between cyclohexanecarbaldehyde (CyCHO) and 2naphtaldehyde (2-naphtCHO) at $-60{ }^{\circ} \mathrm{C}$ allowed Ogoshi et al. to observe the formation a $\mathrm{Ni}(0)$ complex bearing two $\eta^{2}$-carbonyl-coordinated molecules of naphtaldehyde. Upon warming to 25 ${ }^{\circ} \mathrm{C}$, broadening of the formyl hydrogen signals of both aldehydes indicated a possible exchange between coordinated 2-naphtaldehyde and non-coordinated cyclohexyl aldehyde that would generate a much more reactive intermediate $\mathbf{1 8}$ bearing a $\eta^{2}$-carbonyl-coordinated molecule of each aldehyde." This assumption was later corroborated by theoretical calculation on this reaction."2 From 18, two mechanisms were proposed: (i) via a dioxanickelacycle formed by oxidative cyclization of both Ni-coordinated carbonyls (Scheme 33, path A), (ii) via an acylnickel intermediate formed by oxidative addition of the alkyl aldehyde (Scheme 33, path B). On the basis of deuterium labeling experiments conducted with $\mathrm{CyCH}(\mathrm{D}) \mathrm{O}$ and 2-naphtCH(D)O, which showed (i) that the deuterium atoms were incorporated in the methylenic position without loss of enrichment (Scheme 32), and (ii) that $\mathrm{CyCH}(\mathrm{D}) \mathrm{O}$ exhibit a primary kinetic isotope effect (KIE) $\left(k_{\mathrm{\sharp}} / k_{\mathrm{D}}=2.0\right)$ and 2-naphtCH(D)O a secondary $\mathrm{KIE}\left(k_{\mathrm{f}} / k_{\mathrm{b}}=1.2\right)$, Ogoshi et al. concluded that path A was more likely because the secondary KIE was difficult to explain via path B."

Surprisingly, a DFT study conducted on Ogoshi's reaction later revealed that path B involving the mono-carbonyl activation would be energetically more favorable than path A..$^{2}$ The main difficulty of path A would lie in the high-energy demand of the $\beta-\mathrm{H}$ elimination step, whereas in 
contrast, in path B, all steps would be facile. Thus, the overall activation barrier of path B would only be about $20 \mathrm{kcal}^{\mathrm{mol}-\mathrm{H}^{-1}}$ whereas that of path A would be about $50 \mathrm{kcal} . \mathrm{mol}^{-1}$, and the ratedetermining step (ie. the oxidative addition) would only require about $14.5 \mathrm{kcal}^{\mathrm{mol}}{ }^{-1}$. In addition, a natural bond orbital analysis performed on the intermediates and transitions states of the oxidative addition step showed a hybridization change of the carbonyl carbon of the aryl aldehyde from $\mathrm{sp}^{2+s}$ to $\mathrm{sp}^{2.25}$ that could account for the secondary KIE observed with 2naphtCH(D)O by Ogoshi and co-workers. Finally, regarding the reasons of the observed high selectivity of Ogoshi's cross-Tishchenko reaction, the authors of this DFT study demonstrated that it is due, on one hand, to the stronger $\pi$-accepting ability of the aryl aldehyde that favors its coordination to the nickel(0) center (relative to the alkyl aldehyde), and on the other, to the easier oxidative addition of the alkyl aldehyde (relative to the aryl aldehyde)..$^{2}$

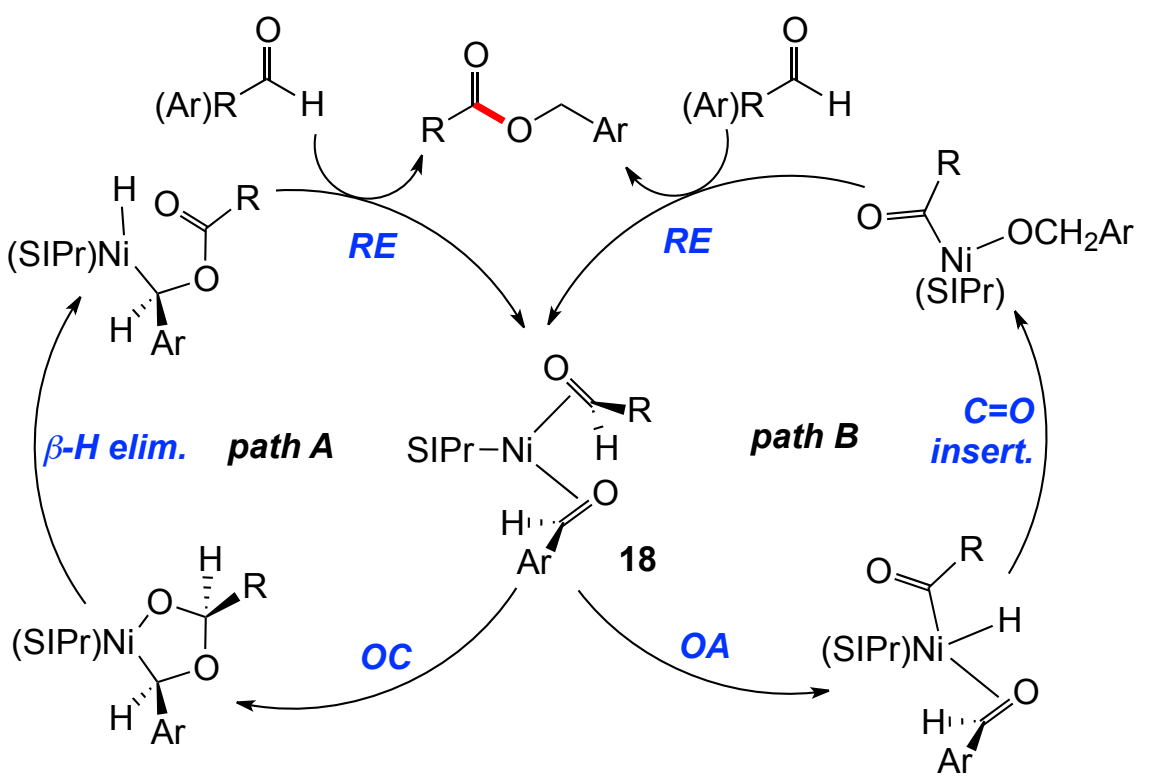

Scheme 33. Possible Mechanisms for the Nickel-Catalyzed Cross-Tishchenko Reaction ${ }^{71,22}$

The only other example of $\mathrm{Ni}(\mathrm{NHC})$-catalyzed carbon-oxygen coupling is the recently reported unified approach for the transformation of aldehyde $\mathrm{C}-\mathrm{H}$ bonds into $\mathrm{C}-\mathrm{O}$ and $\mathrm{C}-\mathrm{N}$ (see 
Section 2.1.2 - Scheme 19) bonds by dehydrogenative cross-coupling. .9 $^{59}$ Thus, in the presence of $\alpha, \alpha, \alpha$-trifluoroacetophenone as hydrogen acceptor, a 1:1 combination of $\mathrm{Ni}(\mathrm{COD})_{2}$ and $\operatorname{IPr}(5$ mol\%) was shown to efficiently couple electron-rich, -neutral and -deficient aromatic aldehydes with primary, secondary, tertiary and benzylic alcohols under mild conditions without notable production of Tishchenko homo-dimer side-product (Scheme 34). In addition, aliphatic aldehydes also underwent this oxidative coupling with alcohols, but required a catalyst loading of $10 \mathrm{~mol} \%$ to give good yields. Finally, preliminary results indicate that a 1:1.1 combination of $\mathrm{Ni}(\mathrm{OTf})_{2}$ and $\mathrm{IPr} . \mathrm{HCl}$ in the presence of $\mathrm{NaOMe}$ as base also catalyze the dehydrogenative coupling of benzaldehyde and $n$-butanol, yet under harder conditions $\left(60{ }^{\circ} \mathrm{C}\right)$ and with reduced efficiency (58\% yield with a catalyst loading of $10 \mathrm{~mol} \%)$.

$$
\begin{aligned}
& \mathrm{Ni}(\mathrm{COD})_{2}(5-10 \mathrm{~mol} \%)
\end{aligned}
$$

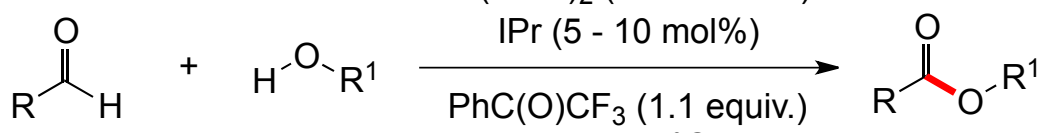

$$
\begin{aligned}
& \text { (1.0 equiv.) (1.0 equiv.) dioxane, } 30{ }^{\circ} \mathrm{C}, 8 \mathrm{~h} \\
& \mathrm{R}=\text { aryl, alkyl } \quad \mathrm{R}^{1}=\text { aryl, } \mathrm{Bn}
\end{aligned}
$$

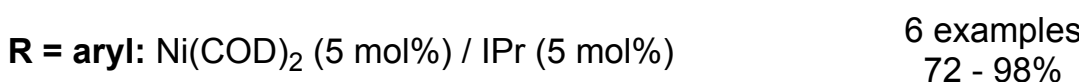

$$
\begin{aligned}
& \mathbf{R}=\text { alkyl: } \mathrm{Ni}(\mathrm{COD}))_{2}(10 \mathrm{~mol} \%) / \operatorname{IPr}(10 \mathrm{~mol} \%) \quad 3 \text { examples }
\end{aligned}
$$

Scheme 34. Dehydrogenative Cross-Coupling of Aldehydes and Alcohols ${ }^{s 9}$

On the basis of literature reports and of control experiments that showed the reduction of the ketone and the decarbonylation of the aldehyde in the absence of a coupling partner, and a KIE of 6.0 in the reaction of benzaldehyde- $d_{1}$ with ethanol, which suggests that $\mathrm{C}-\mathrm{H}$ bond activation is rate-determining, Dong et al. proposed the mechanism depicted in Scheme 33. ${ }^{59}$ Interestingly, it would involve oxidative addition of the aldehyde $\mathrm{C}-\mathrm{H}$ bond after $\eta^{2}$-coordination of both the 
aldehyde and the ketone to the nickel( 0 ) center, and the coordination of the highly $\pi$-accepting ketone would accelerate the oxidative addition, analogously to the path B of the nickel-catalyzed (cross) Tishchenko reaction..$^{11,2}$

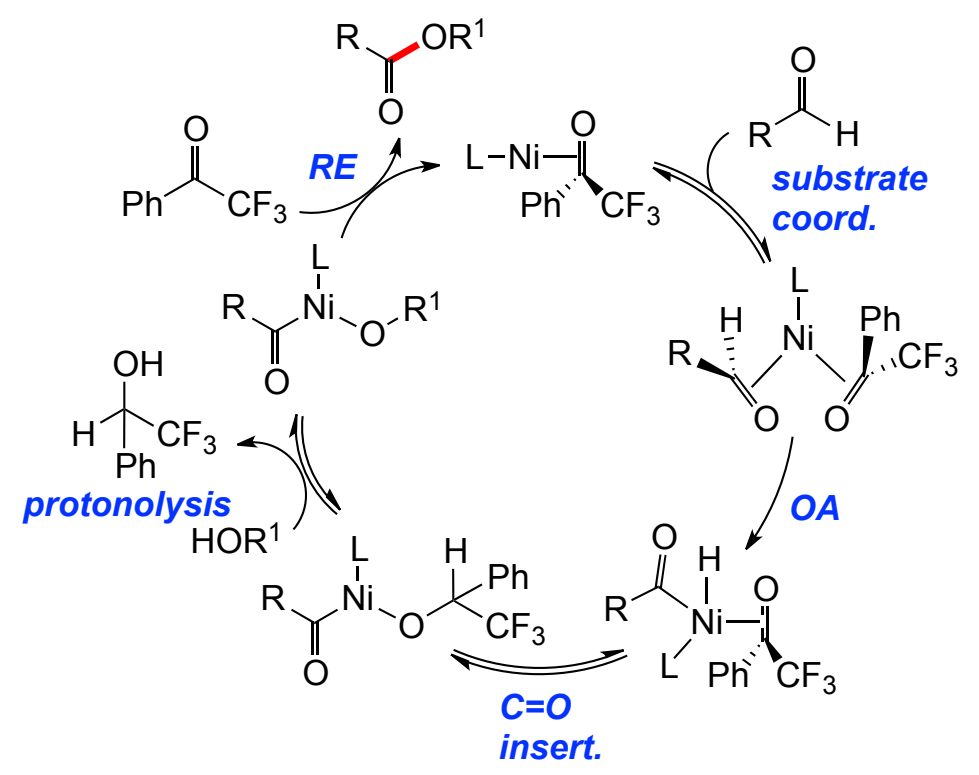

Scheme 35. Proposed Mechanism for the Dehydrogenative Cross-Coupling of Aldehydes and Alcohols $^{\text {s9 }}$

\section{CARBON-BORON BOND FORMATION}

Organoboron compounds are extremely important reagents in organic synthesis..$^{33}$ Along with the transition metal-catalyzed coupling of aryl halides or pseudo-halides with boronyl esters (which is well developed with nickel, but curiously totally unknown with $\mathrm{Ni}(\mathrm{NHC})$ systems ${ }^{10}$, the borylation of unsaturated $\mathrm{C}-\mathrm{C}$ bonds is one of the most powerful methods to synthesize them. ${ }^{74}$ Nevertheless, nickel-catalyzed reactions are rare,,$^{75}$ and to our knowledge the only reported nickel(NHC)-catalyzed example is a $\mathrm{Ni}(\mathrm{COD})_{2} / \mathrm{IMes} \cdot \mathrm{HCl}$ (1:1)-catalyzed borylation of aryl 
cyclopropyl ketones.$^{7}$ Thus, in the presence of bis(pinacolato)diboron, cyclopropyl aryl ketones underwent a $\mathrm{C}-\mathrm{C}$ cleavage of the cyclopropyl ring to yield 4-oxoalkylboronates in moderate to excellent yields (Scheme 36). Interestingly, aryl cylopropyl ketones having a substituent on the cyclopropyl ring gave a single product, as $\mathrm{C}-\mathrm{C}$ bond cleavage selectively took place on the less sterically hindered side.

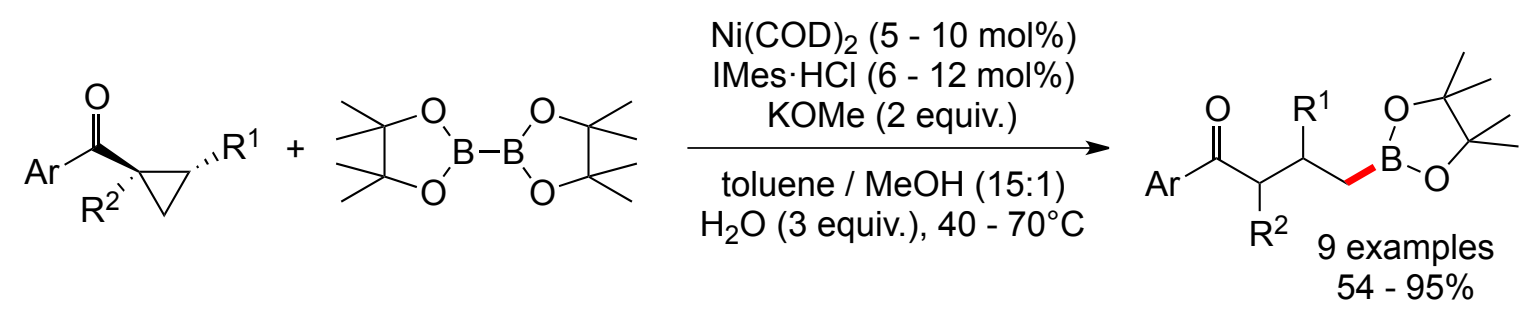

Scheme 36. Borylation of Aryl Cyclopropyl Ketones ${ }^{76}$

Based on the work of Montgomery" and Ogoshi and Kurosawa ${ }^{18}$ on cyclopropyl ketone dimerization, who, respectively, proposed and isolated an oxanickelacyclic intermediate resulting from oxidative addition of cyclopropyl ketone to nickel( 0$)$, the authors proposed the mechanism depicted in Scheme 37. In this mechanism (path A), the oxidative addition leading to the oxanickelacycle would be promoted by the activation of the cyclopropyl ketone by the diboron reagent, and would be followed by transmetalation to give an allylnickel intermediate that bears the boron enolate moiety. Subsequent reductive elimination would regenerate the active nickel( $(0)$ species and produce a boron enolate that would be protonated in situ to give the final 4-oxoalkylboronate compound. Alternatively, the oxanickelacycle could be protonolyzed with $\mathrm{MeOH}$ before transmetalation (Scheme 37, path B). This variant would take into account the possible role of $\mathrm{MeOH}$, which presence is required to observe good yields. However, no further experimental evidence was given to support any of these cycles. 


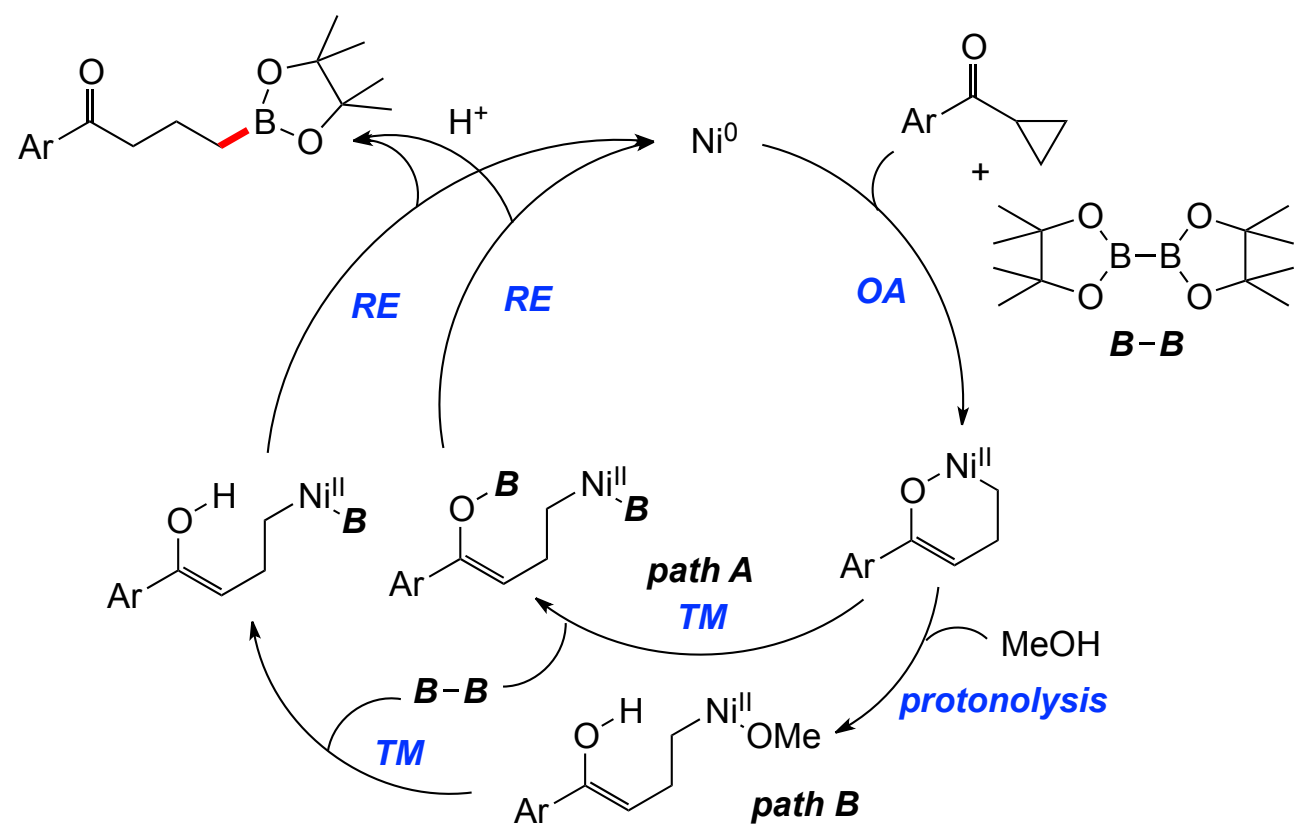

Scheme 37. Proposed Mechanisms for the Borylation of Aryl Cyclopropyl Ketones ${ }^{76}$

Another example of $\mathrm{Ni}(\mathrm{NHC})$-catalyzed $\mathrm{C}-\mathrm{B}$ bond formation recently came from the groups of Chatani and Tobisu with a rare example of borylative cleavage of aromatic $\mathrm{C}-\mathrm{N}$ bonds ${ }^{79}$ In the presence of $\mathrm{Ni}(\mathrm{COD})_{2} / \mathrm{IMes} \cdot \mathrm{HCl}(1: 2-10 \mathrm{~mol} \%)$ and of $\mathrm{NaO} t-\mathrm{Bu}(20 \mathrm{~mol} \%)$, arylamides were shown to react with a diboron reagent to afford the corresponding aryl borylated product in moderate to good yields (Scheme 38). This borylation process was amenable with both cyclic and acyclic amides, and proceeded significantly better with polyaromatic substrates rather than with benzanilides. The same reaction conducted with a hydroborane instead of a diborane, and $\mathrm{PCy}_{3}$ instead of IMes as a ligand afforded the reduction products. Regarding the mechanism, a combination of mercury and filtration tests suggested the reaction to be catalyzed by soluble or nanosized nickel particles rather than by larger nickel aggregates. 


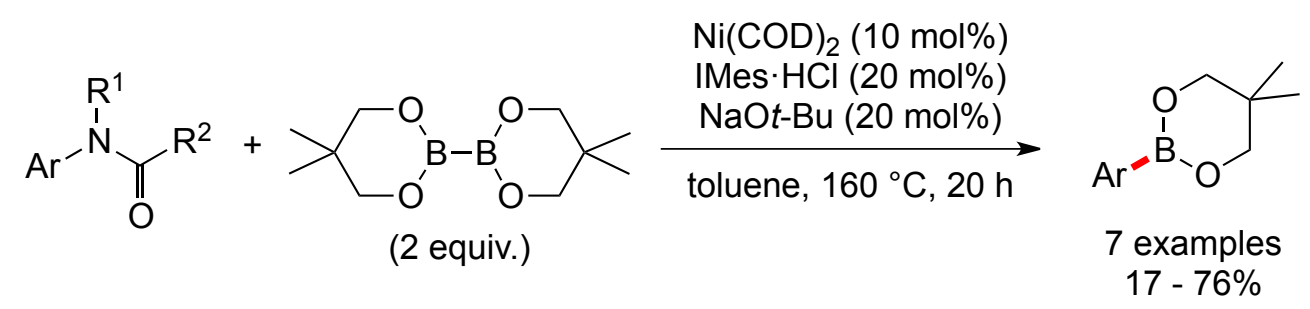

Scheme 38. Borylation of Aromatic C-N Bonds ${ }^{\text {p }}$

Finally the last examples of $\mathrm{Ni}(\mathrm{NHC})$-catalyzed $\mathrm{C}-\mathrm{B}$ bond formation also came from Chatani and Tobisu with the very recent description of the first nickel-catalyzed borylation of arenes and indoles via $\mathrm{C}-\mathrm{H}$ bond activation. ${ }^{\mathrm{s} 0}$ Thus a $\mathrm{Ni}(\mathrm{COD})_{2} / \mathrm{ICy} \cdot \mathrm{HCl}(1: 1)$ catalytic combination (3 mol\%) was demonstrated to promote the borylation of benzene derivatives by reaction with pinacolborane in the presence of a catalytic amount of $\mathrm{NaOt}-\mathrm{Bu}$ with moderate to good efficiency (Scheme 39, eq. 1). With substituted benzenes, the regioselectivity of the reaction was found to be primarily controlled by steric effects, with meta- and para-isomers being the major products, in addition to a benzylic borylated co-product. Whereas heteroaromatics such as furan, thiophene, pyridine and their benzo-fused derivatives were found to be unreactive under these conditions, pyrrole and indoles were smoothly borylated at the 2-position (Scheme 39, eq. 2). Interestingly, $\mathrm{Ni}(\mathrm{COD})_{2}$ could be replaced by the air-stable $\mathrm{Ni}(\mathrm{OAc})_{2}$, which even allowed the borylation of N-methylindole on the gram-scale. Finally, a combination of mercury and filtration tests suggested the reaction to be catalyzed by insoluble nickel particles in this case. 


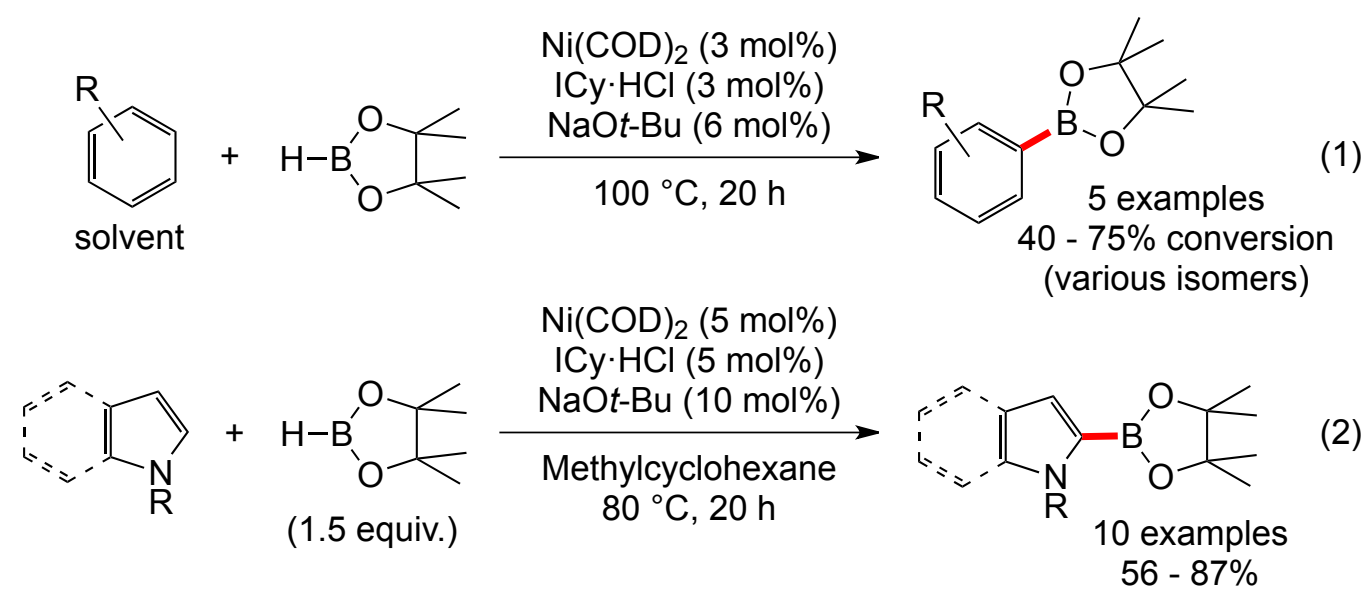

Scheme 39. Borylation of C-H Bonds in Arenes and Indoles ${ }^{\mathrm{so}}$

\section{REDUCTION REACTIONS OF C-HETEROATOM BONDS}

\subsection{Transfer Hydrogenation Reactions}

The use of $\mathrm{Ni}(\mathrm{NHC})$ systems in transfer hydrogenations has so far been limited to one single (and old) example. Fort's versatile catalytic $\mathrm{Ni}(0) / \mathrm{NHC} \cdot \mathrm{HCl} / \mathrm{RONa}$ system (see Scheme 1 for use in aryl aminations) has also been successfully applied in the transfer hydrogenation of imines to the corresponding amines. ${ }^{\text {s1 }}$ Thus, the combination of $\mathrm{Ni}(0) / \mathrm{IMes} \cdot \mathrm{HCl}(5 \mathrm{~mol} \%)$ and of the $\beta-$ hydrogen-containing alkoxide, $\mathrm{Et}_{2} \mathrm{CHONa}$ (5 equiv.), allowed the reduction of a relatively broad range of aldimines and ketimines in good to excellent yields (Scheme 40). The role of the alkoxide is supposed to be similar to what is observed in dehalogenations of aryl halides catalyzed by the same system, , ${ }^{\text {s.83 }}$ and as demonstrated by deuterium labeling experiments, it would notably act as the hydrogen-donor. An observed deuterium isotope effect of $k_{\mathrm{HD}}=3.9$ (with $\mathrm{Et}_{2} \mathrm{CDONa}$ ) suggested that hydrogen elimination in $\mathrm{Et}_{2} \mathrm{CHONa}$ or in a putative nickel alkoxide intermediate would be the rate-determining step. Despite these encouraging results that 
compared favorably with noble metal-based catalysts at the time, no other example has yet been reported.

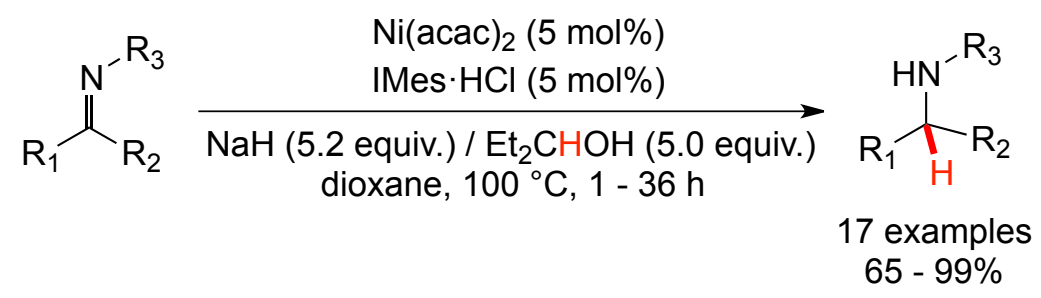

Scheme 40. $\mathrm{Ni}(0) / \mathrm{IMes} \cdot \mathrm{HCl} / \mathrm{Et}_{2} \mathrm{CHONa}-\mathrm{Catalyzed} \mathrm{Transfer} \mathrm{Hydrogenation} \mathrm{of} \mathrm{Imines}{ }^{81}$

\subsection{Hydrosilylation Reactions}

6.2.2. Hydrosilylation of Carbonyl Derivatives. The hydrosilylation of carbonyl functionalities catalyzed by well-defined nickel(II) complexes is poorly developed, ${ }^{84}$ and has only received attention with Ni-NHC systems when Royo's group ${ }^{85}$ and ours ${ }^{86}$ concomitantly disclosed in 2012 two closely related half-sandwich $\mathrm{Ni}(\mathrm{II})-\mathrm{NHC}$ complexes that behave as efficient catalyst precursors for the hydrosilylation of aldehydes and ketones. Thus, the use of the nickel-alkoxide complex 19 that bears a bidentate tetramethylcyclopentadienyl-functionalized NHC ligand (Cp*$\mathrm{NHC}^{\mathrm{m}}$ ) with $\mathrm{PhSiH}_{3}$ allowed the smooth reduction of a few benzaldehyde derivatives as well as of hexanal in only $5 \mathrm{~min}$ at $25^{\circ} \mathrm{C}$ with a catalyst loading as low as $0.5 \mathrm{~mol} \%$ (Scheme 41 , eq. 1). ${ }^{85}$ Reduction of aromatic and aliphatic ketones however required more forcing conditions (toluene, $100{ }^{\circ} \mathrm{C}$ ) to give moderate to high yields of the corresponding alcohols. In contrast, the closely related $\mathrm{Cp}$ complex $\mathbf{1 0 a}$ bearing the simple IMes ligand allowed, in combination with $\mathrm{Ph}_{2} \mathrm{SiH}_{2}$, the reduction at room temperature of a large variety of both aldehydes $(1 \mathrm{~mol} \% \mathrm{10a})$ and 
ketones $\left(5 \mathrm{~mol} \%\right.$ 10a), but required 2 equivalents of $\mathrm{NaHBEt}_{3}$ per $\mathrm{Ni}$ atom as an activator (Scheme 41, eq. 2).86
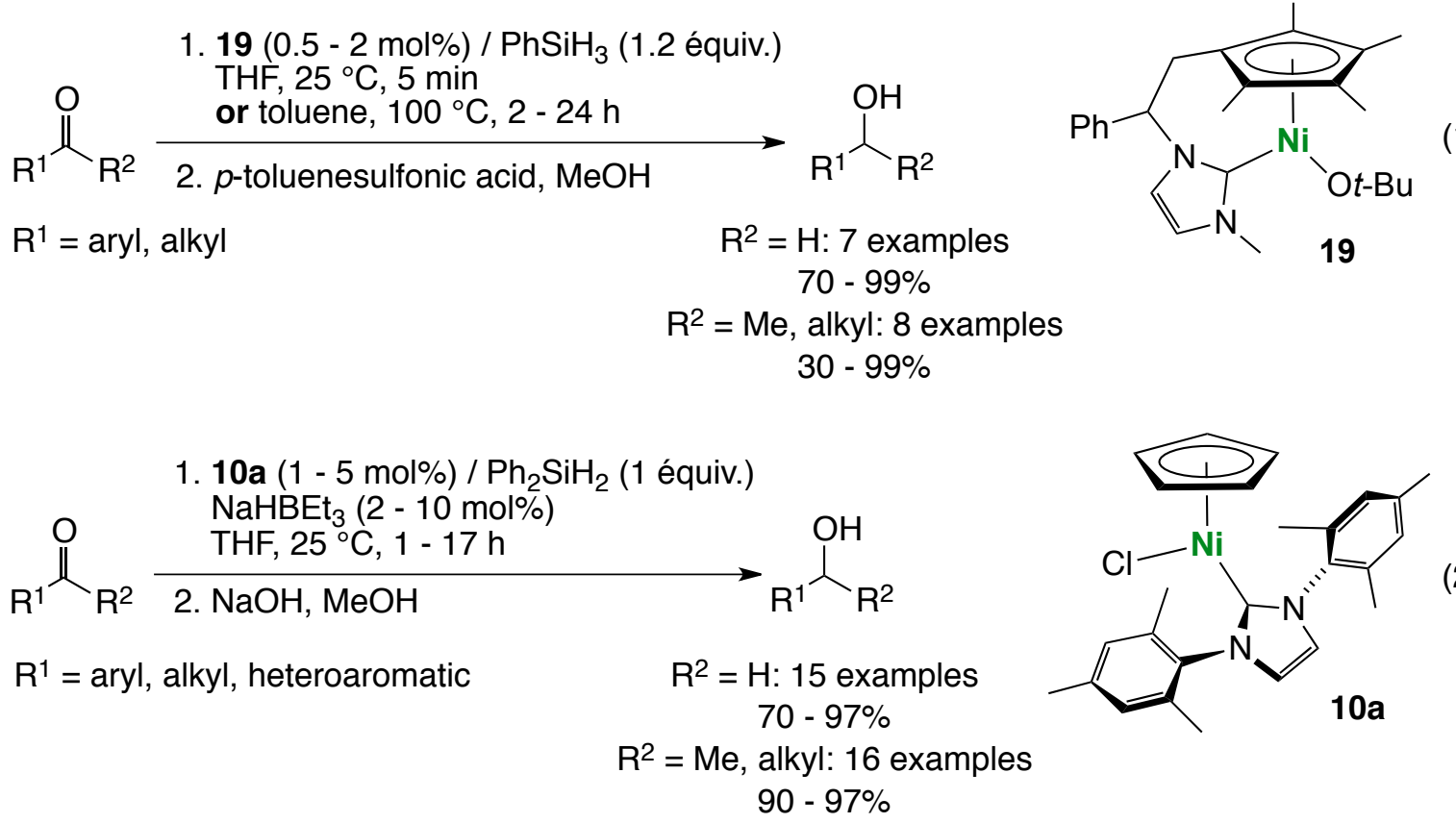

Scheme 41. Hydrosilylation of Aldehydes and Ketones Catalyzed by Complexes $\mathbf{1 9}^{85}$ and 10a ${ }^{86}$

Interestingly stoichiometric reactions of 19 with $\mathrm{PhSiH}_{3}$ (Scheme 42, eq. 1) and of 10a with $\mathrm{KHBEt}_{3}$ (Scheme 42, eq. 2) allowed each group to either identify or isolate a catalytically active nickel hydride intermediate. However, deuterium-labeling experiments run with $\left[\mathrm{Ni}\left(\mathrm{Cp}^{*}\right.\right.$ $\left.\left.\mathrm{NHC}^{\mathrm{Me}}\right) \mathrm{H}\right](\mathbf{2 0}){ }_{, 55}$ and stoichiometric experiments conducted with benzaldehyde that showed no insertion into the $\mathrm{Ni}-\mathrm{H}$ bond of $[\mathrm{Ni}(\mathrm{IMes}) \mathrm{HCp}](\mathbf{2 1}),{ }^{86}$ ruled out the conventional hydride mechanism in both cases. ${ }^{87}$ 
<smiles>CCCC1C2C(C)C(C)=C(C)C(CC(c3ccccc3)N3C=CN(C)C3N1OC(C)(C)C)C2C</smiles>

19

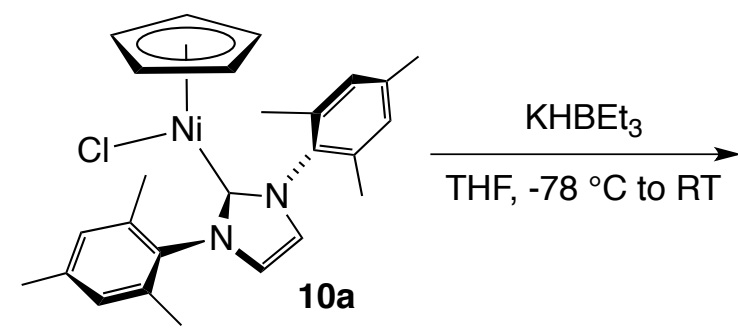

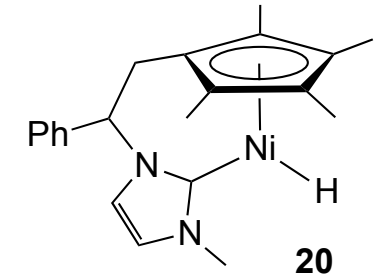
observed by NMR

Scheme 42. Syntheses of the Catalytically Active Nickel Hydride Intermediates $\mathbf{2 0}^{\text {ss }}$ and $\mathbf{2 1}^{\mathrm{s}}$

More recently, Montgomery et al. developed an interesting chemoselective method by using a $\mathrm{Ni}(\mathrm{COD})_{2} / \mathrm{IMes} \cdot \mathrm{HCl}(1: 1)$ combination in the presence of $\mathrm{Ph}_{3} \mathrm{SiH}$ and of catalytic amounts of $\mathrm{KO} t-\mathrm{Bu}{ }^{s 8}$ Indeed, although requiring much higher catalysts loadings than the well-defined precatalysts $10 \mathrm{a}$ and 19 , a notable feature of this method is that, in contrast to most other catalytic hydrosilylation methods, it occurs selectively in the presence of free hydroxyl groups. Hence it provides a convenient one-step procedure for the conversion of hydroxyketones to monoprotected diols, wherein the protecting group is selectively installed on the ketone-derived hydroxyl (Scheme 43).

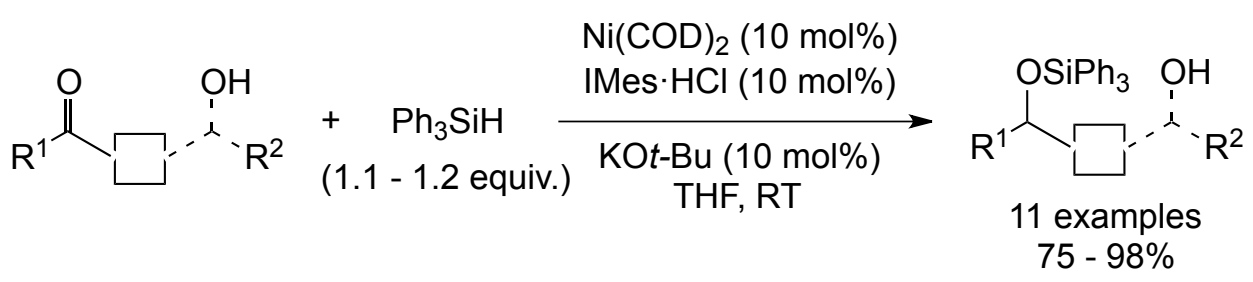

Scheme 43. Chemoselective Hydrosilylation of (Hydroxy)Ketones ${ }^{\mathrm{ss}}$ 
6.2.2. Hydrosilylation of Imines. Nickel has been rarely employed for this reduction reaction, ${ }^{89}$ and the use of $\mathrm{Ni}(\mathrm{NHC})$ systems has to our knowledge been limited to a single example reported by us. Thus, under similar conditions to those established for the hydrosilylation of carbonyl derivatives (see Scheme 39), i.e. in the presence of $\mathrm{Ph}_{2} \mathrm{SiH}_{2}$ (1.0 equiv.) and NaHBEt $(2$ mol\%), 10a $(1 \mathrm{~mol} \%)$ allowed to reduce both aldimines at room temperature and ketimines at $50{ }^{\circ} \mathrm{C}$ (Scheme 44). ${ }^{90}$ Moreover, the cationic derivative of 10a, $[\mathrm{Ni}(\mathrm{IMes})(\mathrm{NCMe}) \mathrm{Cp}]+\mathrm{PF}_{6}(\mathbf{2 2})$, proved also active for these hydrosilylations, and this in the absence of NaHBEt ${ }_{3}$.

The activity of $\mathbf{2 2}$ in the absence of $\mathrm{NaHBEt}_{3}$ raised the question of whether a nickel hydride species was also generated in this case. Control experiments unambiguously demonstrated the formation of the nickel hydride complex 21 by reaction of 22 with $\mathrm{Ph}_{2} \mathrm{SiH}_{2}$, and thus further suggested that this nickel hydride species is a catalytically active intermediate of this "CpNi(IMes)" system in these reactions.

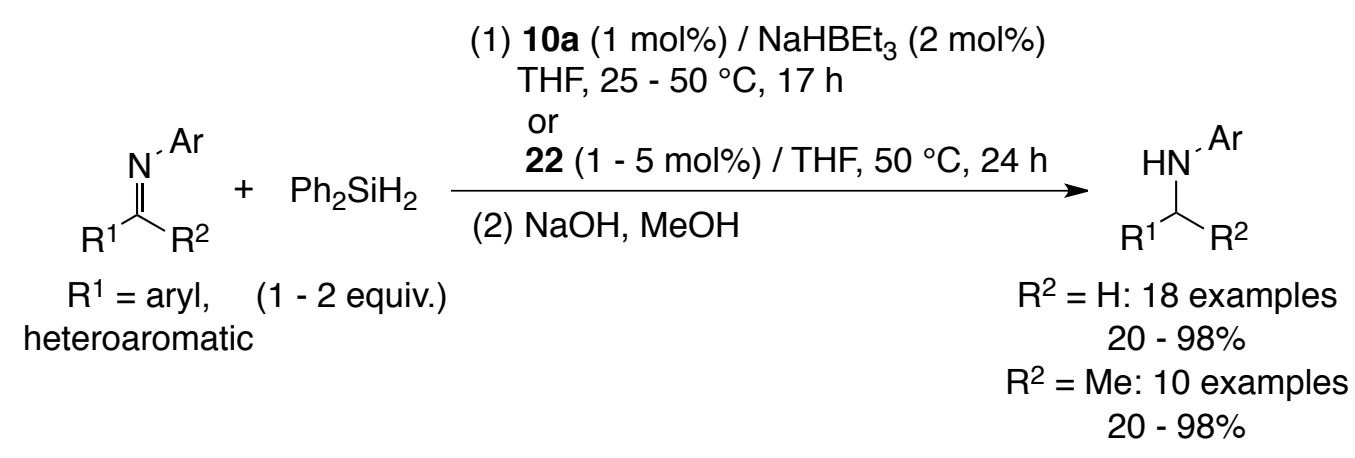

Scheme 44. Hydrosilylation of Aldimines and Ketimines Catalyzed by Complexes 10a and 22

6.3. Miscellaneous Carbon-Heteroatom Bond Reduction. In 2011, Hartwig et al. described an unprecedented selective hydrogenolysis of aromatic $\mathrm{C}-\mathrm{O}$ bonds in aryl alkyl and diaryl ethers that formed exclusively arenes and alcohols. This real breakthrough was achieved by using a 
simple $\mathrm{Ni}(\mathrm{COD})_{2} / \mathrm{SIPr} \cdot \mathrm{HCl}(1: 2)$ combination in the presence of $\mathrm{NaO} t-\mathrm{Bu}$ as base under fairly mild conditions; $100-120{ }^{\circ} \mathrm{C}$ in $m$-xylene under only 1 bar of dihydrogen (Scheme 45$) .^{91}$ In contrast to previous methods with heterogeneous catalysts that required harsh conditions (over $250{ }^{\circ} \mathrm{C}, 30 \mathrm{bar}$ ), hydrogenolysis proceeded here without competing arene ring hydrogenation and reduction of aliphatic $\mathrm{C}-\mathrm{O}$ bonds. Cleavage thus occurred selectively at the $\mathrm{C}_{\mathrm{Ar}}-\mathrm{O}$ bond in the case of alkyl aryl ethers and at the $\mathrm{C}_{\text {ben }}-\mathrm{O}$ bond in the case of benzyl ethers. Moreover hydrogenolysis occurred preferentially at the $\mathrm{C}-\mathrm{O}$ bond adjacent to the more electron-poor aryl ring in the case of unsymmetrical diaryl ethers.

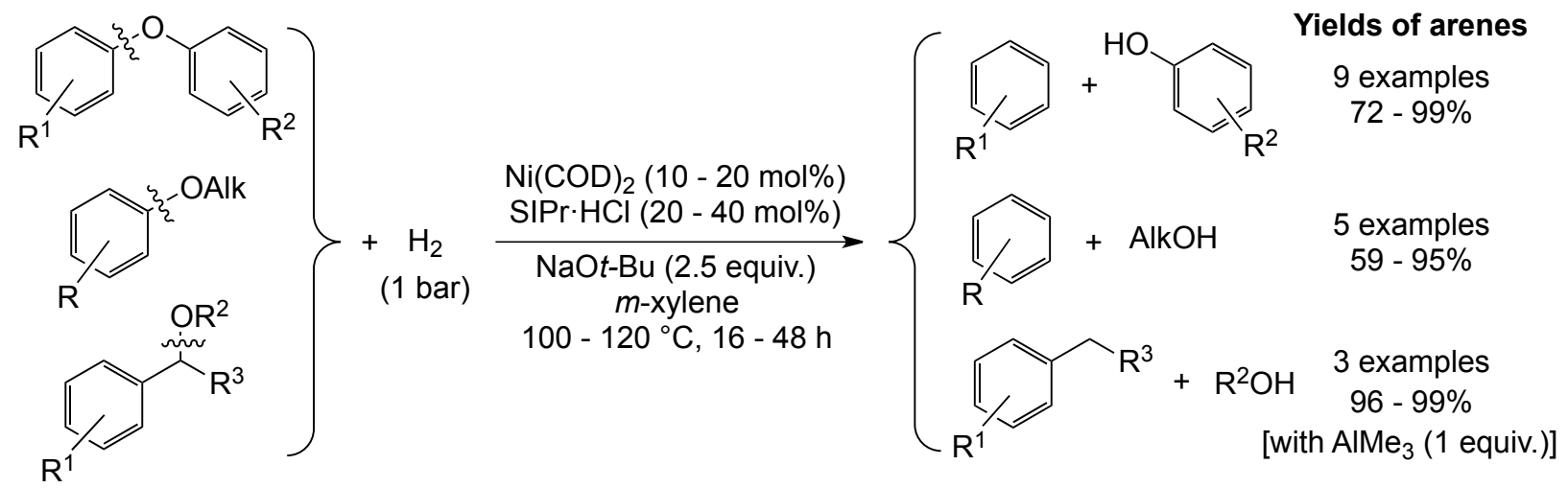

Scheme 45. Selective Hydrogenolysis of Diaryl, Alkyl Aryl and Benzyl Ethers ${ }^{91}$

To probe whether the $\mathrm{Ni}(\mathrm{NHC})$ system reacted as a homogeneous catalysts, the authors conducted a mercury test, that showed no decrease in conversion or product yields. This allowed them to propose that the unprecedented activity and selectivity observed here would result from the homogeneous nature of the catalyst. Unfortunately, no other mechanistic data were collected, and mechanistic insight came only three years later from a DFT study of the hydrogenolysis of diphenyl ether, that showed that the latter is not only the substrate, but also serves as a ligand to stabilize the $\mathrm{Ni}(\mathrm{SIPr})$ active species.92 $\mathrm{Thus,}$ a $\left[\mathrm{Ni}(\mathrm{SIPr})\left(\eta^{6}-\mathrm{PhOPh}\right)\right]^{93}$ complex would form 
initially and rearrange to $\left[\mathrm{Ni}(\mathrm{SIPr})\left(\eta^{2}-\mathrm{PhOPh}\right)\right]$, which would then react according to the three following steps: (i) oxidative addition of diphenyl ether to form $[\mathrm{Ni}(\mathrm{SIPr})(\mathrm{OPh})(\mathrm{Ph})]$, (ii) $\sigma$ complex-assisted metathesis in which $\mathrm{H}_{2}$ would bind to the nickel and benzene (or phenol) would be eliminated, and (iii) reductive elimination of phenol (or benzene) ${ }^{94}$

More recently, Tobisu and Chatani described a similar reductive cleavage of aromatic $\mathrm{C}-\mathrm{O}$ bonds for the conversion of aryl alkyl ethers to arenes, but in the absence of an external reductant. This novel breakthrough was achieved by using a $\mathrm{Ni}(\mathrm{COD})_{2} / \mathrm{I}(2-\mathrm{Ad}) \cdot \mathrm{HCl}(1: 1)$ system in the presence of $\mathrm{NaO} t$ - $\mathrm{Bu}$ in toluene at $160{ }^{\circ} \mathrm{C}$ (Scheme 46$) .{ }^{95}$ Similarly to Hartwig's reaction, cleavage occurred selectively at the $\mathrm{C}_{\mathrm{Ar}}-\mathrm{O}$ bond in the case of aryl alkyl ethers and at the $\mathrm{C}_{\mathrm{ben}}-\mathrm{O}$ bond in the case of benzyl ethers. In contrast however, substrates lacking a fused aromatic ring showed lower reactivity. Importantly, ketone, amide, alkene and pyridine functionalities were well tolerated.

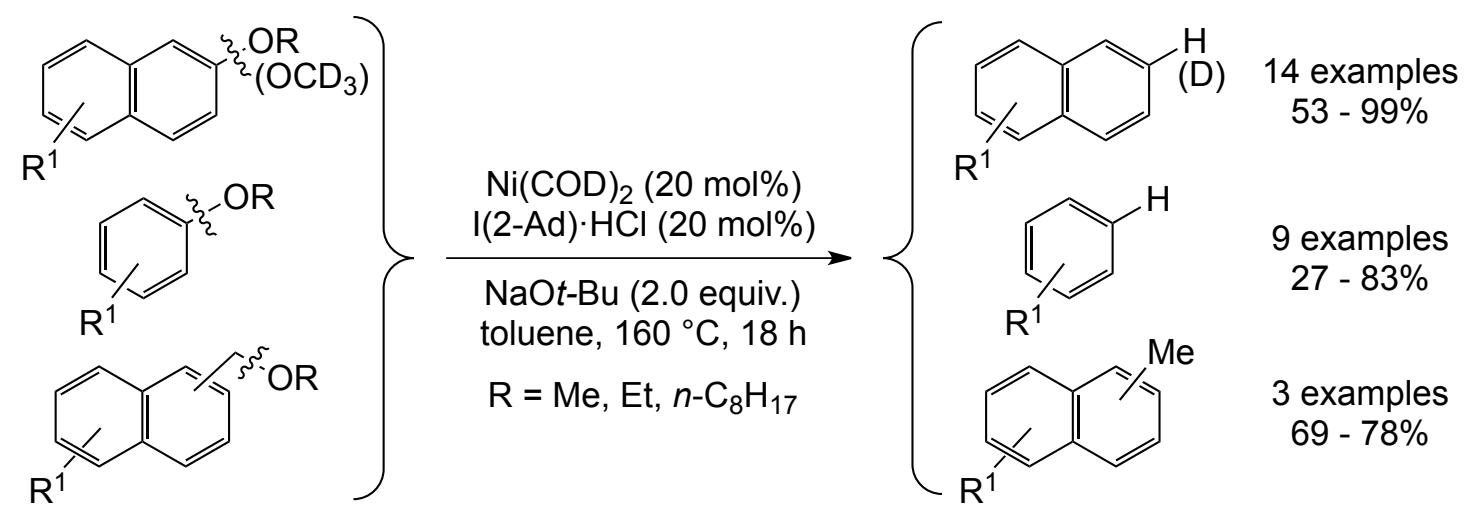

Scheme 46. Reductive Cleavage of Aryl Alkyl Ethers to Arenes in the Absence of External Reductant ${ }^{95}$

Reductive cleavage of the deuterium-labeled 2- $\mathrm{CD}_{3} \mathrm{O}$-naphthalene selectively afforded 2-Dnaphthalene (96\% D - Scheme 46), demonstrating thereof that the hydrogen atom delivered to 
the arene product was coming principally from the alkoxy group of the aryl alkyl ether. On this basis, and on that of a mercury test that showed no reaction inhibition, the authors suggested that the reaction may occur through initial oxidative addition of the $\mathrm{C}-\mathrm{O}$ bond to a soluble nickel(0) species, followed by $\beta$-hydrogen elimination from the aryl-nickel-alkoxide ligand to yield an aryl-nickel-hydride intermediate, and subsequently, reductive elimination. This hypothesis was indirectly confirmed by the quasi-absence of reaction of 2-PhO-naphthalene.

\section{OXIDATION REACTIONS OF C-HETEROATOM BONDS}

In 2009, Navarro et al. described an anaerobic $\mathrm{Ni}(\mathrm{COD})_{2} / \mathrm{IPr} \cdot \mathrm{HCl}(1: 1)$-catalyzed oxidation of secondary alcohols with an aryl halide as a hydride acceptor ${ }^{96}$ Actually, this methodology refers to Fort's system employed for the dehalogenation of aryl halides, in which a secondary alkoxide is used as a hydrogen-donor to form the corresponding ketone as a by-product. ${ }^{82}$ Thus, in the presence of chlorobenzene as an oxidant (1.05 equiv.) and of $\mathrm{KO} t$-Bu as a base, a few secondary aliphatic and aromatic alcohols were converted in 17 to $26 \mathrm{~h}$ in dioxane at $60{ }^{\circ} \mathrm{C}$ to the corresponding ketones in good to excellent yields with an equivalent of benzene as a byproduct. ${ }^{96}$ However, primary benzylic and alkylic alcohols did not undergo oxidation under these conditions.

Further work allowed significant improvements compared to these initial conditions. Using toluene instead of dioxane as solvent, ${ }^{97}$ or free $\operatorname{IPr}$ instead of $\mathrm{IPr} \cdot \mathrm{HCl},{ }^{98}$ allowed important reductions of reaction times, even when carrying out the reactions at room temperature, but it is the use of 2,4-dichlorotoluene as both the oxidant and the solvent that enabled the biggest gain with reactions completed in 15 to $120 \mathrm{~min}$ at 25 to $40{ }^{\circ} \mathrm{C}$ (Scheme 47).98 Furthermore, replacement of the $\mathrm{Ni}(\mathrm{COD})_{2} / \mathrm{IPr} \cdot \mathrm{HCl}$ combination by the air-stable bis-dimethyl fumarate-Ni(0)- 
IPr complex 23 under otherwise similar reaction conditions afforded similar results, and thus avoided the use of the highly air sensitive and pyrophoric $\mathrm{Ni}(\mathrm{COD})_{2}$ (Scheme 47).$^{98}$ Finally the nickel(II) complex 10b also catalyzed the anaerobic oxidation of a couple of alcohols, but under microwave irradiation at $110^{\circ} \mathrm{C} .9^{9}$

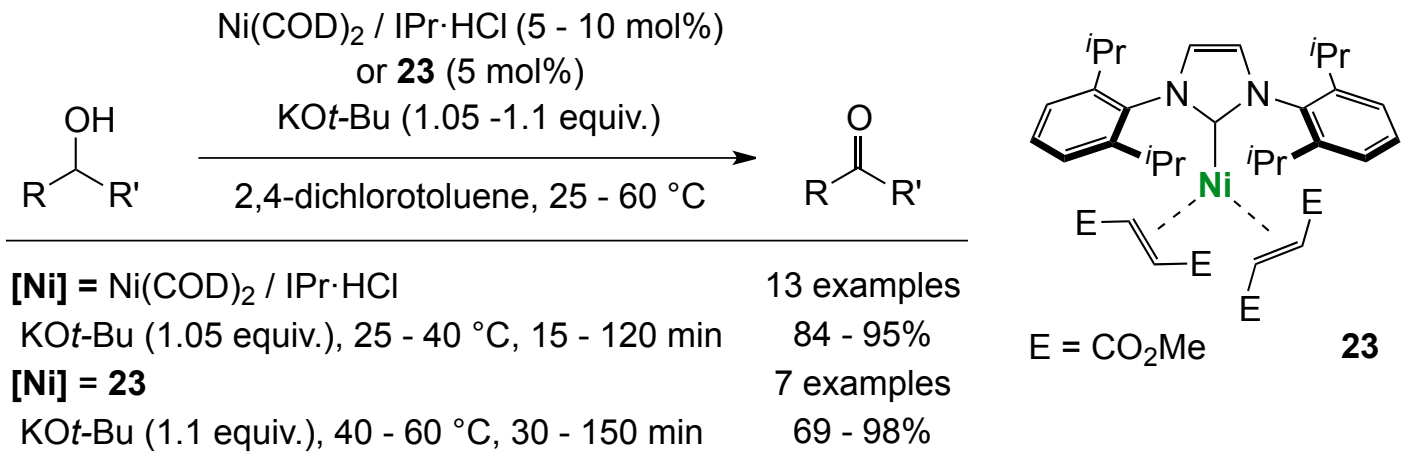

Scheme 47. Anaerobic Oxidation of Secondary Alcohols ${ }^{98}$

\section{CONCLUSION}

Considerable efforts are currently being directed towards the development of nickel catalytic systems as cheaper alternatives to noble metal-based catalysts. In particular, the field of nickel(NHC)-mediated catalysis is increasing exponentially as indicated by the fact than more than $65 \%$ of the discussed research articles in this comprehensive review have been published during the last five and a half years. This collective effort has already led to some unprecedented nickel-catalyzed reactions, such as the dehydrogenative cross-couplings of aldehydes and amines or alcohols, ${ }^{59}$ the borylative cleavage of $\mathrm{C}-\mathrm{N}$ bonds ${ }^{79}$ or the borylation of arenes and indoles via $\mathrm{C}-\mathrm{H}$ bond activation, ${ }^{80}$ as well as to reactions that are not yet amenable with any other transitionmetal catalyst, such as the hydroimination of alkynes, ${ }^{62}$ the highly selective cross-Tishchenko reaction of aliphatic aldehydes with aryl aldehydes,$^{11}$ the selective reductive cleavage of aromatic 
$\mathrm{C}-\mathrm{O}$ bonds in aryl alkyl and diaryl ethers, ${ }^{9195}$ and the fascinating one-step indoline synthesis under nickel/photoredox dual catalysis. ${ }^{63}$ These unprecedented reactions perfectly illustrate the developing potential and breadth of application of $\mathrm{Ni}(\mathrm{NHC})$ catalysts.

Nevertheless, efforts still need to be driven towards notably:

(i) the reduction of catalyst loadings, which are still rather high, notably with in situ generated $\mathrm{Ni}(\mathrm{NHC})$ systems (the $\mathrm{Ni}(\mathrm{acac})_{2} / \mathrm{IPr} \cdot \mathrm{HCl}$-catalyzed arylamination with PMHS as a reducing agent described by Knochel being one notable exception ${ }^{x}$ )

(ii) the development of easier-to-handle nickel sources rather than the very sensitive and highly flammable $\mathrm{Ni}(\mathrm{COD})_{2}$, which is still often used,

(iii) a better understanding of the reaction mechanisms, as well as a better knowledge of the $\mathrm{Ni}(\mathrm{NHC})$ catalysts' stabilities and ways of degradation, as these will allow new insights into catalyst improvement, and could eventually lead to the recycling of homogeneous $\mathrm{Ni}(\mathrm{NHC})$ catalysts.

Achieving these goals will necessitate detailed mechanistic studies combining experimental and theoretical work, as well as the design of novel well-defined complexes bearing NHC ligands with fined tuned electronic and steric properties, as exemplified by the replacement of IPr by IPr*owe in complexes 10a and 11, which allowed much better results in aryl amination and/or aryl thiolation, ${ }^{5356}$ or by the use of the 1,2,4-triazole based NHC complexes 13a,b that are the only known $\mathrm{Ni}(\mathrm{NHC})$ species known to be active in the hydroamination reactions. ${ }^{61}$ Providing that these efforts will be done, $\mathrm{Ni}(\mathrm{NHC})$-based catalysts will not just become a low-cost replacement of $\operatorname{Pd}(\mathrm{NHC})$ systems but a brilliant complement, which will allow difficult organic transformations, that are not amenable with other metals, to proceed with great efficiency. 


\section{AUTHOR INFORMATION}

\section{Corresponding Author}

*E-mail: michael.chetcuti@unistra.fr. Tel: +33 3 68852631.*E-mail: vritleng@unistra.fr.

\section{Notes}

The authors declare no competing financial interest.

\section{ACKNOWLEDGMENT}

We are grateful to the Université de Strasbourg and the CNRS for their financial help. The Agence Nationale de la Recherche is also acknowledged for its support to V.R. and the doctoral fellowship of M.H. (ANR 2010 JCJC 716 1; SBA-15-NHC-NiCat). V. R. also thanks the Institut Universitaire de France for its support.

\section{ABBREVIATIONS}

acac, acetylacetonate; bpy, 2,2'-bipyridine; COD, $\eta^{4}$-cyclooctadiene; $\mathrm{Cp}, \eta^{\text {s-cyclopentadienyl; }}$ $\mathrm{Cp}^{*-\mathrm{NHC}^{\mathrm{Mc}}}$, 1-[1-phenyl-2-(2,3,4,5-tetramethylcyclopentadienyl)ethyl-3-methyl-imidazol-2ylidene; DME, 1,2-dimethoxyethane; DMF, dimethylformamide; DIPP, 2,6-diisopropylphenyl; I(2-Ad), 1,3-(2-adamantyl)imidazole-2-ylidene; IBn, 1,3-dibenzylimidazol-2-ylidene; ICy, 1,3dicyclohexylimidazol-2-ylidene; IMes, 1,3-dimesitylimidazol-2-ylidene; IPent, 1,3-bis(2,6dipentan-3-ylphenyl)imidazol-2-ylidene; IPr, 1,3-bis(2,6-diisopropylphenyl)imidazol-2-ylidene; IPrCl, 1,3-bis(2,6-diisopropylphenyl)-4,5-dichloroimidazol-2-ylidene; IPr*, 1,3-bis[2,6bis(diphenylmethyl)-4-methylphenyl]imidazol-2-ylidene; IPr*owe, 1,3-bis[2,6bis(diphenylmethyl)-4-methoxyphenyl]imidazol-2-ylidene; $\operatorname{IPr}^{*_{\mathrm{rol}}}, 1,3-b i s[2,6-b i s(\mathrm{di}-p$ tolylmethyl)-4-methylphenyl]imidazol-2-ylidene; ItBu, 1,3-di-tert-butylimidazol-2-ylidene; $\mathrm{KIE}$, kinetic isotopic effect; $\mathrm{KO}$-Am, potassium tert-amylate; Mes, 2,4,6-trimethylphenyl; OA, 
oxidative addition; OC, oxidative cyclization; Ph-Bpin, phenylboronic acid pinacol ester; RE, reductive elimination; SIMes, 1,3-dimesitylimidazolidin-2-ylidene; SIPr, 1,3-bis(2,6diisopropylphenyl)-imidazolidin-2-ylidene; THF, tetrahydrofuran; TM, transmetalation.

TABLE OF CONTENT GRAPHIC

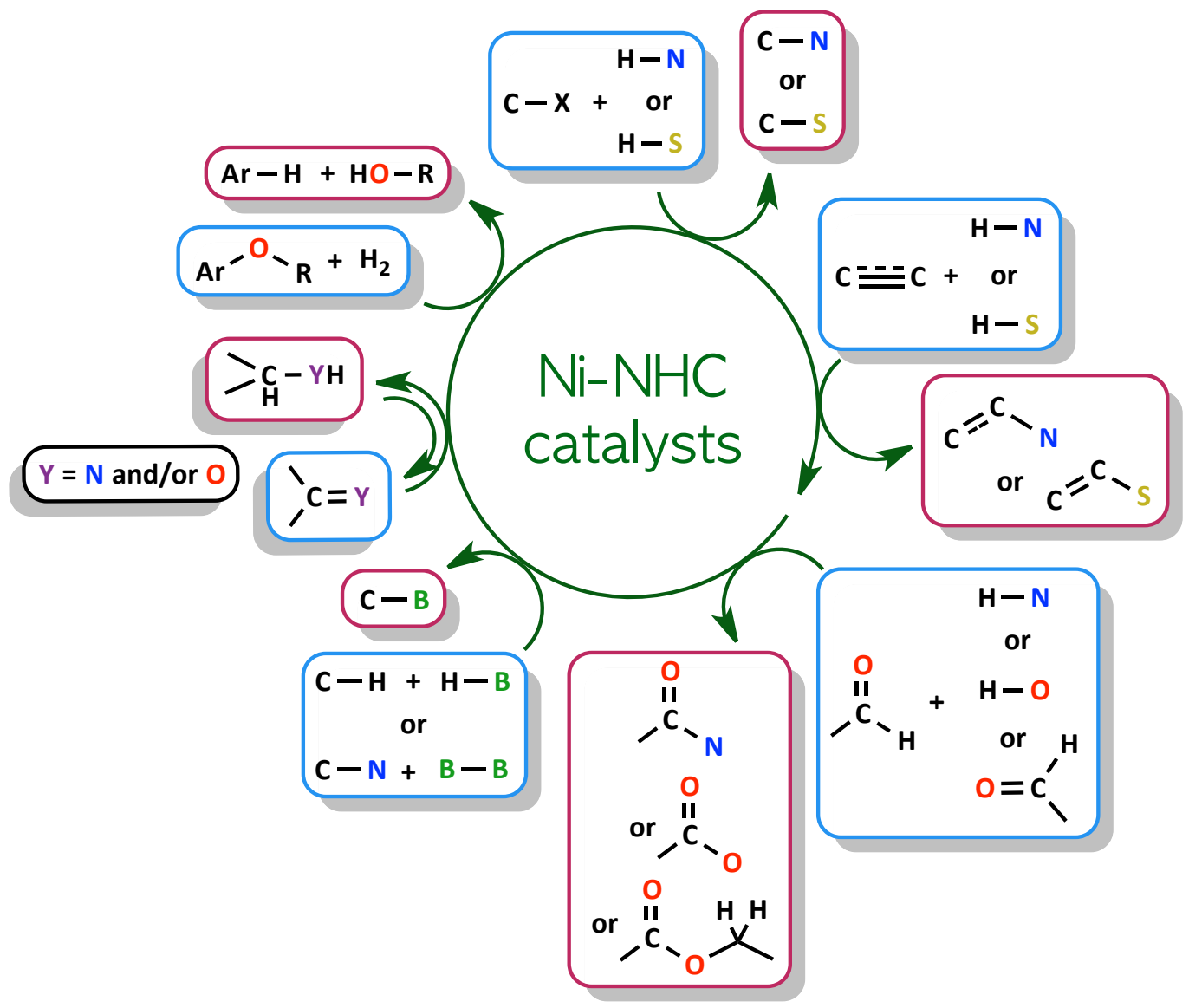

\section{REFERENCES}

(1) The Organic Chemistry of Nickel; Academic Press: New York, 1974; Vol. 1.

(2) Ziegler, K.; Holzkamp, E.; Breil, H.; Martin, H. Angew. Chem. 1955, 67, 541-547.

(3) Keim, W. Angew. Chem. Int. Ed. 1990, 29, 235-244. 
(4) Bini, L.; Müller, C.; Vogt D. Chem. Commun. 2010, 46, 8325-8334.

(5) (a) Keim, W. Angew. Chem. Int. Ed. 2013, 52, 12492-12496. (b) Kuhn, P.; Sémeril, D.; Matt, D.; Chetcuti, M. J.; Lutz, P. Dalton Trans. 2007, 515-528.

The Nobel Prize in 2010.

http://www.nobelprize.org/nobel_prizes/chemistry/laureates/2010/ (accessed July 29, 2015).

(7) (a) The Mizoroki-Heck Reaction; Oestreich, M., Ed.; Wiley-VCH: Chichester, U.K., 2009. (b) Negishi, E.-i. Angew. Chem. Int. Ed. 2011, 50, 6738-6794. (c) uzuki, A. Angew. Chem. Int. Ed. 2011, 50, 6722-6737.

(8) European Commission. Report on Critical Raw Materials for the EU. May 2014. http://ec.europa.eu/enterprise/policies/raw-materials/files/docs/crm-report-on-critical-rawmaterials_en.pdf (accessed July 29, 2015).

(9) For excellent overviews of recent advances in homogeneous nickel catalysis: (a) Tasker, S. Z.; Standley, E. A.; Jamison, T. F. Nature 2014, 509, 299-309. (b) Ananikov, V. P. ACS Catal. 2015, 5, 1964-1971.

(10) Rosen, B. M.; Quasdorf, K. W.; Wilson, D. A.; Zhang, N.; Resmerita, A.-M.; Garg, N. K.; Percec, V. Chem.Rev. 2011, 111, 1346-1416.

(11) Li, B.-j.; Yu, D.-G.; Sun, C.-L.; Shi, Z.-J. Chem. Eur. J. 2011, 17, 1728-1759.

(12) (a) Böhm, V. P. W.; Gstöttmayr, C. W. K.; Weskamp, T.; Herrmann W. A. Angew. Chem. Int. Ed. 2001, 40, 3387-3389. (b) Schaub, T.; Backes, M.; Radius, U. J. Am. Chem. Soc. 2006, 
128, 15964-15965. (c) Tobisu, M.; Xu, T.; Shimasaki, T.; Chatani, N. J. Am. Chem. Soc. 2011, $133,19505-19511$.

(13) (a) Camasso, N. M.; Sanford, M. S. Science 2015, 347, 1218-1220. (b) Mitra, R.; Pörschke, K.-R. Angew. Chem. Int. Ed. 2015, 54, 7488-7490.

(14) See for example: Schley, N. D.; Fu, G. C. J. Am. Chem. Soc. 2014, 136, 16588-16593.

(15) Biswas, S.; Weix, D. J. J. Am. Chem. Soc. 2013, 135, 16192-16197.

(16) (a) Tellis, J. C.; Primer, D. N.; Molander, G. A. Science 2014, 345, 433-436. (b) Zuo, Z.; Ahneman, D. T.; Chu, L.; Terret, J. A.; Doyle, A. G.; MacMillan, D. W. C. Science 2014, 345, $437-440$.

(17) Cornella, J.; Gómez-Bengoa, E.; Martin, R. J. Am. Chem. Soc. 2013, 135, 1997-2009.

(18) Arduengo, A. J. III; Harlow, R. L.; Kline, M. J. Am. Chem. Soc. 1991, 113, 361-363.

(19) Benhamou, L.; Chardon, E.; Lavigne, G.; Bellemin-Laponnaz, S.; César, V. Chem. Rev. 2011, 111, 2705-2733.

(20) (a) Frenking, G.; Solà, M.; Vyboishchikov, S. F. J. Organomet. Chem. 2005, 690, 61786204. (b) Radius, U.; Bickelhaupt, F. M. Coord. Chem. Rev. 2009, 253, 678-686. (c) Jacobsen, H.; Correa, A.; Poater, A.; Costabile, C.; Cavallo, L. Coord. Chem. Rev. 2009, 253, 687-703. (d) Nelson, D. J.; Nolan, S. P. Chem. Soc. Rev. 2013, 42, 6723-6753.

(21) For general reviews and books dealing with N-heterocyclic carbenes and their benefits in modern chemistry and transition-metal catalysis, see: (a) N-Heterocyclic Carbenes in Transition 
Metal Catalysis; Glorius, F., Ed.; Springer-Verlag: Heidelberg, Germany, 2007; Topics in Organometallic Chemistry; Vol. 21. (b) Díez-González, S.; Marion, N.; Nolan, S. P. Chem. Rev. 2009, 109, 3612-3676. (c) Hopkinson, M. N.; Richter, C.; Schedler, M.; Glorius, F. Nature 2014, 510, 485-496.

(22) (a) Louie, J. Ni-NHC mediated catalysis. In N-Heterocyclic Carbenes in Synthesis; Nolan, S. P., Ed.; Wiley-VCH: Weinheim, Germany, 2006; pp 163-182. (b) Gu, S.; Ni, P.; Chen, W. Chin. J. Catal. 2010, 31, 875-886. (c) Fort, Y.; Comoy C. NHC-Nickel and Platinum complexes. In N-Heterocyclic Carbenes: From Laboratory Curiosities to Efficient Synthetic Tools; DíezGonzález, S., Ed.; RSC Publishing: Cambridge, U.K., 2011; pp 284-326. (d) Haynes, M. T. II; Jackson, E. P.; Montgomery, J. Nickel Complexes of N-Heterocyclic Carbenes. In $N$ Heterocyclic Carbenes: Effective Tools for Organometallic Synthesis, 1" ed.; Nolan, S. P., Ed.; Wiley-VCH: Weinheim, Germany, 2014; pp 371-396. (e) Prakasham, A. P.; Ghosh, P. Inorg. Chim. Acta 2015, 431, 61-100.

(23) For our complementary review targeting $\mathrm{C}-\mathrm{C}$ bond forming reactions and their mechanistic aspects, see: Henrion, M.; Ritleng, V.; Chetcuti, M. J. ACS Catal. 2015, 5, 12831302.

(24) (a) Wolfe, J. P.; Wagaw, S.; Marcoux, J.-F.; Buchwald, S. L. Acc. Chem. Res. 1998, 31, 805-818. (b) Hartwig, J. F. Angew. Chem., Int. Ed. Engl. 1998, 37, 2046-2067. (c) Muci, A. R.; Buckwald, S. L. Top. Curr. Chem. 2002, 219, 131-209. (d) Kienle, M.; Dubbaka, S. R.; Brade, K.; Knochel, P. Eur J. Org. Chem. 2007, 4166-4176. (e) Surry, D. S.; Buchwald, S. L. Angew. Chem. Int. Ed. 2008, 47, 6338-6361. (f) Hartwig, J. F. Acc. Chem. Res. 2008, 41, 1534-1544. 
(25) Gradel, B.; Brenner, E.; Schneider, R.; Fort, Y. Tetrahedron Lett. 2001, 42, 5689-5692.

(26) Desmarets, C.; Schneider, R.; Fort, Y. J. Org. Chem. 2002, 67, 3029-3036.

(27) Omar-Amrani, R.; Thomas, A.; Brenner, E.; Schneider, R.; Fort, Y. Org. Lett. 2003, 5, $2311-2314$.

(28) Kuhl, S.; Fort, Y.; Schneider, R. J. Organomet. Chem. 2005, 690, 6169-6177.

(29) Manolikakes, G.; Gavryushin, A.; Knochel, P. J. Org. Chem. 2008, 73, 1429-1434.

(30) Hie, L.; Ramgren, S. D.; Mesganaw, T.; Garg, N. K. Org. Lett. 2012, 14, 4182-4185.

(31) Fine Nathel, N. F.; Kim, J.; Hie, L.; Jiang, X.; Garg, N. K. ACS Catal. 2014, 4, 32893293.

(32) Jiang, J.; Zhu, H.; Shen, Y.; Tu, T. Org. Chem. Front. 2014, 1, 1172-1175.

(33) (a) Morrell, D. G.; Kochi, J. K. J. Am. Chem. Soc. 1975, 97, 7262-7270. (b) Tsou, T. T.; Kochi, J. K. J. Am. Chem. Soc. 1979, 101, 6319-6332. (c) Tsou, T. T.; Kochi, J. K. J. Am. Chem. Soc. 1979, 101, 7547-7560.

(34) Chen, C.; Yang, L.-M. J. Org. Chem. 2007, 72, 6324-6327.

(35) For a recent paper presenting air-stable $\left[\mathrm{Ni}\left(\mathrm{PR}_{3}\right)_{2}(\right.$ Aryl $\left.) \mathrm{X}\right]$ complexes as easy-to-handle and efficient entries into homogeneous Ni(0) catalysts, see: Standley, E. A.; Smith, S. J.; Müller, P.; Jamison, T. F. Organometallics 2014, 33, 2012-2018.

(36) Fan, X.-H.; Li, G.; Yang, L.-M. J. Organomet. Chem. 2011, 696, 2482-2484. 
(37) Gao, C.-Y.; Yang, L.-M. J. Org. Chem. 2008, 73, 1624-1627.

(38) Huang, J.-H.; Yang, L.-M. Org. Lett. 2011, 13, 3750-3753.

(39) (a) Tamao, K.; Sumitani, K.; Kumada, M. J. Am. Chem. Soc. 1972, 94, 4374-4376. (b)

Percec, V.; Bae, J.-Y.; Hill, D. H. J. Org. Chem. 1995, 60, 1060-1065.

(40) Wu, W.; Fan, X.-H.; Zhang, L.-P.; Yang, L.-M. RSC Adv. 2014, 4, 3364-3367.

(41) (a) Tobisu, M.; Shimasaki, T.; Chatani, N. Chem. Lett. 2009, 38, 710-711. (b) Tobisu, M.; Yasutome, A.; Yamakawa, K.; Shimasaki, T.; Chatani, N. Tetrahedron 2012, 68, 5157-5161.

(42) Shimasaki, T.; Tobisu, M.; Chatani, N. Angew. Chem. Int. Ed. 2010, 49, 2929-2932.

(43) Mesganaw, T.; Silberstein, A. L.; Ramgren, S. D.; Fine Nathel, N. F.; Hong, X.; Liu, P.; Garg, N. K. Chem. Sci. 2011, 2, 1766-1771.

(44) Ramgren, S. D.; Silberstein, A. L.; Yang, Y.; Garg, N. K. Angew. Chem. Int. Ed. 2011, 50, $2171-2173$.

(45) Ackermann, L.; Sandmann, R.; Song, W. Org. Lett. 2011, 13, 1784-1786.

(46) See also: Mesganaw, T.; Garg, N. K. Org. Process Res. Dev. 2013, 17, 29-39.

(47) Kashin, A. S.; Ananikov, V. P. J. Org. Chem. 2013, 78, 11117-11125.

(48) Matsubara, K.; Miyazaki, S.; Koga, Y.; Nibu, Y.; Hashimura, T.; Matsumoto, T. Organometallics 2008, 27, 6020-6024.

(49) Matsubara, K.; Ueno, K.; Koga, Y.; Hara, K. J. Org. Chem. 2007, 72, 5069-5076. 
(50) Nagao, S.; Matsumoto, T.; Koga, Y.; Matsubara, K. Chem. Lett. 2011, 40, 1036-1038.

(51) (a) Jones, G. D.; Martin, J. L.; McFarland, C.; Allen, O. R.; Hall, R. E.; Haley, A. D.; Brandon, R. J.; Konovalova, T.; Desrochers, P. J.; Pulay, P.; Vicic, D. A. J. Am. Chem. Soc. 2006, 128, 13175-13183. (b) Manolikakes, G.; Knochel, P. Angew. Chem. Int. Ed. 2009, 48, 205-207. (c) Gao, C.-Y.; Cao, X.; Yang, L.-M. Org. Biomol. Chem. 2009, 7, 3922-3925.

(52) Kelly, R. A. III; Scott, N. M.; Díez-González, S.; Stevens, E. D.; Nolan, S. P. Organometallics 2005, 24, 3442-3447.

(53) Martin, A. R.; Makida, Y.; Meiries, S.; Slawin, A. M. Z.; Nolan, S. P. Organometallics 2013, 32, 6265-6270.

(54) Iglesias, M. J.; Prieto, A.; Nicasio, M. C. Adv. Synth. Catal. 2010, 352, 1949-1954.

(55) (a) Marion, N.; Navarro, O.; Mei, J.; Stevens, E. D.; Scott, N. M.; Nolan, S. P. J. Am. Chem. Soc. 2006, 128, 4101-4111. (b) Navarro, O.; Marion, N.; Mei, J.; Nolan, S. P. Chem. Eur. J. 2006, 12, 5142-5148. (c) For a very recent study on this topic, see: Melvin, P. R.; Balcells, D.; Hazari, N.; Nova, A. ACS Catal. 2015, 5, 5596-5606 and references therein.

(56) Martin, A. R.; Nelson, D. J.; Meiries, S.; Slawin, A. M. Z.; Nolan, S. P. Eur. J. Org. Chem. 2014, 3127-3131.

(57) Iglesias, M. J.; Blandez, J. F.; Fructos, M. R.; Prieto, A.; Álvarez, E.; Belderrain, T. R.; Nicasio, M. C. Organometallics 2012, 31, 6312-6316.

(58) Rull, S. G.; Blandez, J. F.; Fructos, M. R.; Belderrain, T. R.; Nicasio, M. C. Adv. Synth. Catal. 2015, 357, 907-911. 
(59) Whittaker, A. M.; Dong, V. M. Angew. Chem. Int. Ed. 2015, 54, 1312-1315.

(60) (a) Huang, L.; Arndt, M.; Gooßen, K.; Heydt, H.; Gooßen, L. J. Chem. Rev. 2015, 115, 2596-2697. (b) Rodriguez-Ruiz, V.; Carlino, R.; Bezzenine-Lafollée, S.; Gil, R.; Prim, D.; Schulz, E.; Hannedouche, J. Dalton Trans. 2015, 44, 12029-12059.

(61) Dash, C.; Shaikh, M. M.; Butcher, R. J.; Ghosh, P. Dalton Trans. 2010, 39, 2515-2524.

(62) Manan, R. S.; Kilaru, P.; Zhao, P. J. Am. Chem. Soc. 2015, 137, 6136-6139.

(63) Tasker, S. Z.; Jamison, T. F. J. Am. Chem. Soc. 2015, 137, 9531-9534.

(64) Zhang, Y.; Ngeow, K. C.; Ying, J. Y. Org. Lett. 2007, 9, 3495-3498.

(65) See for instance: Mann, G.; Baranano, D.; Hartwig, J. F.; Rheingold, A. L.; Guzei, I. A. J. Am. Chem. Soc. 1998, 120, 9205-9219.

(66) Guan, P.; Cao, C.; Liu, Y.; Li, Y.; He, P.; Chen, Q.; Liu, G.; Shi, Y. Tetrahedron Lett. 2012, 53, 5987-5992.

(67) Yoon, H.-J.; Choi, J.-W.; Kang, H.; Kang, T.; Lee, S.-M.; Jun, B.-H.; Lee, Y.-S. Synlett 2010, 2518-2522.

(68) Malyshev, D. A.; Scott, N. M.; Marion, N.; Stevens, E. D.; Ananikov, V. P.; Beletskaya, I. P.; Nolan, S. P. Organometallics 2006, 25, 4462-4470.

(69) Seki, T.; Nakajo, T.; Onaka, M. Chem. Lett. 2006, 35, 824-829.

(70) Ogoshi, S.; Hoshimoto, Y.; Ohashi, M. Chem. Commun. 2010, 46, 3354-3356. 
(71) Hoshimoto, Y.; Ohashi, M.; Ogoshi, S. J. Am. Chem. Soc. 2011, 133, 4668-4671.

(72) Yu, H.; Fu, Y. Chem. Eur. J. 2012, 18, 16765-16773.

(73) (a) Contemporary Boron Chemistry; Davidson, M. G., Hugues, A. K., Marder, T. B., Wade, K., Eds.; RSC: Cambridge, U.K., 2000. (b) Miyaura, N. Metal-Catalyzed Cross-Coupling Reactions of Organoboron Compounds with Organic Halides. In Metal-Catalyzed CrossCoupling Reactions, $2^{\text {nd }}$ ed.; de Meijere, A., Diederich, F., Eds.; Wiley-VCH: Weinheim, Germany, 2004; pp 41-124. (c) Boronic Acids: Preparation and Applications in Organic Synthesis, Medicine and Materials, $2^{\text {nd }}$ ed.; Hall, D. G., Ed.; Wiley-VCH: Weinheim, Germany, 2011.

(74) For seminal work, see: Ishiyama, T.; Matsuda, N.; Miyaura, N.; Suzuki, A. J. Am. Chem. Soc. 1993, 115, 11018-11019.

(75) (a) Beletskaya, I.; Moberg, C. Chem. Rev. 1999, 99, 3435-3462. (b) Yu, C.-M.; Youn, J.; Yoon, S.-K.; Hong, Y.-T. Org. Lett. 2005, 7, 4507-4510. (c) Hirano, K.; Yorimitsu, H.; Oshima, K. Org. Lett. 2007, 9, 5031-5033. (d) Cho, H. Y.; Morken, J. P. J. Am. Chem. Soc. 2008, 130, 16140-16141. (e) Sumida, Y.; Yorimitsu, H.; Oshima, K. Org. Lett. 2008, 10, 4677-4679.

(76) Sumida, Y.; Yorimitsu, H.; Oshima, K. J. Org. Chem. 2009, 74, 3196-3198.

(77) Liu, L.; Montgomery, J. J. Am. Chem. Soc. 2006, 128, 5348-5349.

(78) Ogoshi, S.; Nagata, M.; Kurosawa, H. J. Am. Chem. Soc. 2006, 128, 5350-5351.

(79) Tobisu, M.; Nakamura, K.; Chatani, J. Am. Chem. Soc. 2014, 136, 5587-5590. 
(80) Furukawa, T.; Tobisu, M.; Chatani, N. Chem. Commun. 2015, 51, 6508-6511.

(81) Kuhl, S.; Schneider, R.; Fort, Y. Organometallics 2003, 22, 4184-4186.

(82) Desmarets, C.; Kuhl, S.; Schneider, R.; Fort, Y. Organometallics 2002, 21, 1554-1559.

(83) Kuhl, S.; Schneider, R.; Fort, Y. Adv. Synth. Catal. 2003, 345, 341-344.

(84) (a) Fontaine, F.-G.; Nguyen, R.-V.; Zargarian, D. Can. J. Chem. 2003, 81, 1299-1306. (b) Chakraborty, S.; Krause, J. A.; Guan, H. Organometallics 2009, 28, 582-586. (c) Tran, B. L.; Pink, M.; Mindiola, D. J. Organometallics 2009, 28, 2234-2243. (d) Kundu, S.; Brennessel, W. W.; Jones, W. D. Inorg. Chem. 2011, 50, 9443-9453. (e) Porter, T. M.; Hall, G. B.; Groy, T. L.; Trovitch, R. J. Dalton Trans. 2013, 42, 14689-14692. (f) MacMillan, S. N.; Harman, W. H.; Peters, J. C. Chem. Sci. 2014, 5, 590-597. (g) Czerny, F.; Döhlert, P.; Weidauer, M.; Irran, E.; Enthaler, S. Inorg. Chim. Acta 2015, 425, 118-123.

(85) Postigo, L.; Royo, B. Adv. Synth. Catal. 2012, 354, 2613-2618.

(86) Bheeter, L. P.; Henrion, M.; Brelot, L.; Darcel, C.; Chetcuti, M. J.; Sortais, J.-B.; Ritleng, V. Adv. Synth. Catal. 2012, 354, 2619-2624.

(87) Shirobokov, O. G.; Kuzmina, L. G.; Nikonov, G. I. J. Am. Chem. Soc. 2011, 133, 64876489.

(88) Lage, M. L.; Bader, S. J.; Sa-ei, K.; Montgomery, J. Tetrahedron 2013, 69, 5609-5613.

(89) Vetter, A. H.; Berkessel, A. Synthesis 1995, 419-422. 
(90) Bheeter, L. P.; Henrion, M.; Chetcuti, M. J.; Darcel, C.; Ritleng, V.; Sortais, J.-B. Catal. Sci. Technol. 2013, 3, 3111-3116.

(91) Sergeev, A. G.; Hartwig, J. F. Science 2011, 332, 439-443.

(92) Sawatlon, B.; Wititsuwannakul, T.; Tantirungrotechai, Y.; Surawatanawong, P. Dalton Trans. 2014, 43, 18123-18133.

(93) For the preparation of $\left[\mathrm{Ni}(\mathrm{NHC})\left(\eta^{6}\right.\right.$-arene $\left.)\right]$ complexes under similar conditions, see: Hoshimoto, Y.; Hayashi, Y.; Suzuki, H.; Ohashi, M.; Ogoshi, S. Organometallics 2014, 33, $1276-1282$.

(94) This mechanism contrasts with that established for the $\mathrm{Ni}(\mathrm{COD})_{2} / \mathrm{PCy}_{3}(1: 2)$-catalyzed reductive cleavage of aryl alkyl ether's $\mathrm{C}_{\mathrm{axy}}-\mathrm{O}$ bonds with silanes as reducing agents, where all key intermediates involve $\mathrm{Ni}(\mathrm{I})$, see ref. 17.

(95) Tobisu, M.; Morioka, T.; Ohtsuki, A.; Chatani, N. Chem. Sci. 2015, 6, 3410.

(96) Berini, C.; Brayton, D. F.; Mocka, C.; Navarro, O. Org. Lett. 2009, 11, 4244-4247.

(97) Berini, C.; Navarro, O. Chem. Commun. 2012, 48, 1538-1540.

(98) Berini, C.; Winkelmann, O. H.; Otten, J.; Vicic, D. A.; Navarro, O. Chem. Eur. J. 2010, $16,6857-6860$.

(99) Landers, B.; Navarro, O. Inorg. Chim. Acta 2012, 380, 350-353. 